\title{
Photoacoustic insight for aerosol light absorption aloft from meteorological aircraft and comparison with particle soot absorption photometer measurements: DOE Southern Great Plains climate research facility and the coastal stratocumulus imposed perturbation experiments
}

\author{
W. Patrick Arnott, ${ }^{1}$ John W. Walker, ${ }^{1}$ Hans Moosmüller, ${ }^{1}$ Robert A. Elleman, ${ }^{2}$ \\ Haflidi H. Jonsson, ${ }^{3}$ Gintautas Buzorius, ${ }^{3}$ William C. Conant,${ }^{4}$ Richard C. Flagan, ${ }^{4}$ \\ and John H. Seinfeld ${ }^{4}$ \\ Received 10 March 2005; revised 16 June 2005; accepted 10 August 2005; published 24 January 2006
}

[1] Aerosol light absorption can be intense close to local sources such as wildland and oil fires, with smoke that disperses into the boundary layer and, with enough lift, into the upper atmosphere where it may be transported around the globe. Filter-based methods such as the Particle Soot Absorption Photometer (PSAP) are most commonly used to quantify aerosol light absorption aloft. This paper reports first measurements of aerosol light absorption aloft with photoacoustic instrumentation (PA). Three examples of aerosol light absorption are presented. The first one illustrates a case of detached layers aloft arising from intercontinental, interoceanic transport of smoke from wildland fires in Siberia to the North American continent and the measurement campaign held at the Department of Energy Atmospheric Radiation Measurement Program Climate Research Facility in north central Oklahoma. Then, two examples of intense local fire smoke light absorption from the Coastal Stratocumulus Imposed Perturbation Experiment near Marina, California, USA, are presented. The first local fire was an oil fire burning in a storage tank near Moss Landing, California, USA, and smoke from this fire was very dark, indicating a low single scattering albedo. By contrast, the second local fire was predominantly burning wood, vegetation, and structures near Fort Ord in Marina, California, USA, and the smoke was very bright, indicating a high single scattering albedo. In all examples, PA measurements at $676 \mathrm{~nm}$ were compared with those from a PSAP modified to measure at three wavelengths, including $660 \mathrm{~nm}$.

Citation: Arnott, W. P., J. W. Walker, H. Moosmüller, R. A. Elleman, H. H. Jonsson, G. Buzorius, W. C. Conant, R. C. Flagan, and J. H. Seinfeld (2006), Photoacoustic insight for aerosol light absorption aloft from meteorological aircraft and comparison with particle soot absorption photometer measurements: DOE Southern Great Plains climate research facility and the coastal stratocumulus imposed perturbation experiments, J. Geophys. Res., 111, D05S02, doi:10.1029/2005JD005964.

\section{Introduction}

[2] Aerosol light absorption and scattering are the main pathways for particulate interaction with atmospheric radiation. Regions downwind of major urban areas are impacted by light absorbing aerosol, chiefly black carbon from combustion sources, and health, radiation, and cloud lifetime issues are associated with these particles [Andreae,

\footnotetext{
${ }^{1}$ Division of Atmospheric Sciences, Desert Research Institute, Reno, Nevada, USA.

${ }^{2}$ Department of Atmospheric Sciences, University of Washington, Seattle, Washington, USA.

${ }^{3}$ Naval Postgraduate School, Monterey, California, USA.

${ }^{4}$ California Institute of Technology, Pasadena, California, USA.

2001]. These particles may mix into the atmospheric boundary layer, or get lofted into the upper atmosphere by convective processes. Wildland fires also produce black carbon that may very well be transported into the upper atmosphere during large fires. In these cases where aerosol are in the upper atmosphere their characterization cannot be inferred by in situ measurements at ground level.

[3] Black carbon absorbs light across the entire solar spectrum and typically has an inverse wavelength dependence where light absorption at blue wavelengths is greater than it is at red wavelengths. This is not always the case, as was noted recently [Kirchstetter et al., 2004] where evidence was presented that light absorption by wildland fire smoke may have a very different wavelength dependence. Aerosol light absorption, both on the ground and aloft, is most often measured using filter-based methods such as the Particle Soot Absorption Photometer (PSAP), and a new 
three-wavelength instrument has been developed for both applications [Virkkula et al., 2005].

[4] Measurements aloft are usually undertaken on rare occasions when groups assembled to analyze particular hypotheses initiate an intensive operational period. An exception to this is the program at the Department of Energy Atmospheric Radiation Program Climate Research Facility Southern Great Plains site, denoted simply as the SGP in the remainder of this paper. Aerosol light scattering and PSAP absorption measurements are measured routinely in the boundary layer over the SGP using an unpressurized single-engine light aircraft. This program may grow in coming years, both in terms of the number of measurements and in the aircraft capability. One finding of this routine sampling program aloft is an indication that aerosol single scattering albedo systematically diminishes with height. Single scattering albedo is defined as the ratio of light scattering to the sum of light scattering and absorption, also known as extinction. The significance of this finding is that such an effect would stimulate relative heating of the atmosphere at levels above the ground where clouds try to form, and would tend to shadow the ground from direct radiative forcing by sunlight with potential implications to reductions of photosynthetic plant growth and the initiation of convection. Aerosol amount at the SGP is usually modest, though can be larger during episodes where farmers burn local fields [Sheridan et al., 2001; Arnott et al., 2003b]. Aerosol amount, and the potential for strong aerosol impacts, is much larger in places like Brazil where the rain forest is being cleared by the slash and burn method [Reid et al., 1998].

[5] The most common method of aerosol light absorption measurement involves use of a filter to sample ambient air and an optical source and detector to determine the change in filter transmittance or reflectance due to particulate matter deposited on the filter since the previous optical measurement. Filter optical transmittance measurement is the most common of analytical method and single- and multiplewavelength versions of these instruments are commercially available, called Aethalometers by Magee Scientific, and PSAP's by Radiance Research. Aethalometers are calibrated by the manufacturer to provide black carbon mass concentration, though recent efforts have sought to interpret data from these instruments also in terms of aerosol light absorption [Weingartner et al., 2003; Arnott et al., 2005b]. Single-wavelength PSAP's have been calibrated to provide aerosol light absorption measurements [Bond et al., 1999], and a new three-wavelength prototype has been developed and calibrated [Virkkula et al., 2005] during the Reno Aerosol Optics Study [Sheridan et al., 2005]. It is this new prototype that will be compared in this paper with photoacoustic measurements of aerosol light absorption aloft. It has been recognized that the optical characterization of particles on quartz fiber filters common to these instruments formally involves multiple scattering theory [Horvath, 1997; Gorbunov et al., 2002], and that nonabsorbing aerosol gives rise to an apparent absorption equal to roughly $2 \%$ of the scattering coefficient [Bond et al., 1999; Arnott et al., 2005b; Virkkula et al., 2005]. A strong motivation for use of the photoacoustic instrument on aircraft is to provide a separate method for aerosol light absorption measurement that does not employ filters, and a method that can have its calibration evaluated using light absorbing gases such as $\mathrm{NO}_{2}$ [Arnott et al., 2000; Sheridan et al., 2005] to compare with the more commonly used PSAP, and to characterize the atmosphere.

[6] It should be noted that filter-based measurements of aerosol light absorption are quite sensitive, as the multiple scattering enhancement of light absorption by the filter substrate amplifies the absorption signal, yet the challenge is to provide suitable calibration. The largest remaining unknown factor is the effect of particle distribution in the filter since a monolayer of particles sitting on the filter surface will have an optical effect quite different from the same particles embedded uniformly throughout the filter. A new filter-based instrument has been developed as the Multiple Angle Absorption Photometer (MAAP) by Thermo Electron that measures both filter transmission and reflection at numerous angles to better constrain the energy budget for the optical interaction of the filter and particles [Petzold and Schönlinner, 2004; Petzold et al., 2005] by obtaining absorptivity from ( 1 - filter transmissivity - filter reflectivity). The MAAP does not require ancillary use of a nephelometer for determination of the scattering coefficient needed to correct filter transmission measurements as does the PSAP and the Aethalometer.

[7] Surface measurements of aerosol light absorption in the ambient, and from source samples, by the photoacoustic method, have been reported by several groups [Bruce and Pinnick, 1977; Terhune and Anderson, 1977; Japar and Killinger, 1979; Roessler and Faxvog, 1980; Japar and Szkarlat, 1981; Roessler, 1984; Adams et al., 1990a, 1990b; Petzold and Niessner, 1992, 1994, 1995; Moosmüller et al., 1998; Arnott et al., 1999, 2003b, $2005 \mathrm{~b}]$. While this list covers the flavor of most previous efforts, it is not meant to be complete. However, no references have been found for previous measurements of aerosol light absorption aloft from a meteorological aircraft by the photoacoustic method, but are reported in this paper. It should be noted that a remarkable report has been made of photoacoustic measurements of water vapor and $\mathrm{NO}$ concentrations at an altitude of $28 \mathrm{~km}$ using a large tethered balloon system that was operated by the National Center for Atmospheric Research and flew out of Palestine Texas [Patel et al., 1974].

[8] An extensive literature exists on photoacoustic trace gas detection and it is relevant to discuss the general merits of this spectroscopic method. Use of high-quality microphones (e.g., $1^{\prime \prime}$ diameter capacitive versions that polarize the plates with an externally provided $200 \mathrm{~V}$ ) as detectors gives a dynamic range for acoustic pressure measurements from around $-40 \mathrm{~dB}(\operatorname{Re} 20 \mu \mathrm{Pa})$ to around $135 \mathrm{~dB}(\mathrm{Re}$ $20 \mu \mathrm{Pa}$ ). The acoustic signal at the low end of this range is $2 \times 10^{-7} \mathrm{~Pa}$, and as light absorption levels aloft generally are low, it is a challenge to accurately quantify such low sound pressure values. These detectors are completely colorblind in that they can be used with radiant energy at any wavelength, are stable over many years, and a well-aligned unit has negligible background. Relatively simple acoustical shielding and use of analog acoustic filters to block certain frequency ranges can allow these instruments to be used for source sample measurements for even very loud tethered jet aircraft [Arnott et al., 2005a]. At the low signal level phase sensitive lock-in amplifier detection and large laser power are additionally needed to optimize sensitivity. 
[9] This paper is organized as follows. Section 2 covers the acoustical issues associated with use of resonant photoacoustic instruments aloft in an environment where ambient pressure can change rather quickly. This discussion is rather technical and is specialized toward instrument issues so the reader eager for intercomparisons of filter-based measurements with photoacoustic values can skip this section on a first read and go directly to the next section. Examples are given in this next section illustrating measurements aloft above the atmospheric boundary layer of distinct layers of aerosol light absorption from wildland fires at source locations an ocean and $1 / 2$ of a continent away from the observation area. Further examples illustrate use of the instrument to characterize locally intense plumes of aerosol light absorption from very dark smoke emitted during a fuel oil fire and from very bright smoke from a wildland fire.

\section{Resonant Photoacoustics Aloft: Acoustical Considerations}

[10] Photoacoustic instruments have been used both in source and ambient sampling of light absorbing aerosol. Sample air is pulled continuously through an acoustical resonator and is illuminated by laser light that is power modulated at the acoustical resonance frequency. Light absorption results in particle heating and this heat transfers rapidly to the surrounding air, inducing periodic pressure fluctuations that are picked up with a microphone on the resonator. This is a rather generic description of the photoacoustic method, though key points about the ability to sample continuously, to accommodate microphone calibration by balancing the static pressure on both sides of the membrane, and to acoustically shield the instrument from background noise and coherent window light absorption signals can be found elsewhere [Rosengren, 1975; Arnott et al., 1999, 2003a, 2005a].

[11] The photoacoustic instrument operates at a convenient wavelength of $676 \mathrm{~nm}$ where gaseous interference is negligible and where a diode laser source is available that allows for direct electronic modulation of the optical power at the resonator frequency. The laser power is around $500 \mathrm{~mW}$ at the operating acoustical resonance frequency of nominally $1500 \mathrm{~Hz}$, and the laser is fiber-coupled to the resonator. The multimode fiber output is collimated with a lens attached to the fiber end. The lens is attached directly to the resonator to minimize effects of aircraft vibration on optical alignment, though as the beam did not proceed completely cleanly through the resonator a background signal of around $10 \mathrm{Mm}^{-1}$ was observed from absorption of light by the resonator walls. A misaligned system produces a very large amount of stray light in comparison with the aligned system where light scattering particles are present. The lens system used at the time of these experiments had no alignment capacity, though in later work employing a more sophisticated lens system, stray radiation has been eliminated.

[12] It has been demonstrated that ammonium sulfate aerosol of a pure scattering nature at $532 \mathrm{~nm}$, with negligible light absorption, produce negligible photoacoustic signals [Arnott et al., 2005b; Sheridan et al., 2005]. The absorption measured by the photoacoustic instrument for ammonium sulfate aerosol was perhaps $0.77 \mathrm{Mm}^{-1}$ and the scattering coefficient was $519 \mathrm{Mm}^{-1}$ for a single scattering albedo of 0.9985 . By comparison, the Aethalometer had a filter attenuation coefficient of around $27 \mathrm{Mm}^{-1}$ at $521 \mathrm{~nm}$ while the scattering-corrected PSAP had an absorption coefficient of $2.2 \mathrm{Mm}^{-1}$ at $550 \mathrm{~nm}$ for this case.

[13] In any case, the slightly misaligned photoacoustic instrument with a relative broad laser beam diameter necessitated background subtraction through the use of a motorized valve that switched between sample air and air filtered of particles, and the valve position was automatically changed under computer control as part of the operation of the instrument control software. Data were acquired at a rate of $1 \mathrm{~Hz}$ and instrument zeros were obtained every 500 measurements. The background measurement was time averaged over 10 measurements to improve the signal-tonoise ratio for background determination. It should be noted that in other instances a properly aligned system with a clean laser beam from a solid state laser at $532 \mathrm{~nm}$ exhibited negligible background so no background subtraction was necessary [Arnott et al., 2003b].

[14] Photoacoustic signal background could generally arise from two sources. Electronic background could arise from bleed of the modulation square wave signal to the microphone data acquisition channel. This background source would be independent of pressure and temperature. On the other hand, stray laser light being absorbed somewhere, for example on a window or on the resonator wall, could give rise to a background photoacoustic signal that is dependent on the thermodynamic conditions of the gas in the resonator. Extensive tests have demonstrated that the electronic background is negligible. The goal of the remaining section is to develop an understanding of the operation of the photoacoustic instrument aloft where pressure, relative humidity, and ambient temperature may change dramatically on timescales of minutes. Photoacoustic light absorption is obtained from

$$
\beta_{\text {abs }}=\frac{P_{\text {mic }}}{P_{\text {Laser }}} \frac{A_{\text {res }}}{\gamma(R H)-1} \frac{\pi^{2} f_{0}(T, P, R H)}{Q(T, P, R H)}=\frac{P_{\text {mic }}}{P_{\text {Laser }}} \frac{A_{\text {res }}}{\gamma-1} \frac{\pi^{2} f_{0}}{Q},
$$

where $P_{\text {mic }}$ is the microphone pressure, $P_{\text {laser }}$ is the laser power, $A_{\text {res }}$ is the cross-sectional area of the resonator, $\gamma$ is the ratio of isobaric to isochoric specific heats, $f_{0}$ is the resonance frequency, and $Q$ is the quality factor of the resonator [Arnott et al., 1995, 1999, 2000, 2003b; Raspet et al., 2003]. The first form of equation (1) indicates the explicit dependencies on pressure, temperature, and $\mathrm{RH}$. Relative humidity, temperature, and pressure are measured downstream of the photoacoustic resonator. The resonance frequency and quality factor are also measured every 100 to $200 \mathrm{~s}$ using a piezoelectric transducer attached to the resonator. The resonance scan is accomplished in about $3 \mathrm{~s}$ as 5 points are used at different frequencies along with a routine to determine the resonance frequency and quality factor from a fit of the resulting curve to a theoretical expression with 3 parameters. The third parameter is the peak acoustic pressure at resonance. Though it is not needed in equation (1) to determine light absorption, it is very useful to have available as a means of quantifying microphone calibration and performance over time, and its dependence on 
ambient conditions is a good check on the viability of making sound pressure measurements aloft.

[15] Equation (1) indicates that several parameters are a function of relative humidity $(\mathrm{RH})$, temperature and pressure. It is instructive to consider the dependence of these thermophysical parameters on environmental conditions of temperature, pressure and $R H$. First, define the fraction of water vapor molecules as $h$, and note that it is given by

$$
h=0.01 R H(\%) \frac{e(T)}{P}
$$

where the saturation vapor pressure of water vapor at temperature $T$ is

$$
e(T)=6.11(m b) \exp \left[\frac{a\left(T-T_{0}\right)}{T-b}\right]
$$

with $a=17.269, b=35.860$, and $T_{0}=273.15$ for $T>$ $273.15 \mathrm{~K}$. The value of $\gamma$ for moist air is

$$
\gamma=\frac{7+h}{5+h}
$$

Consider a relatively extreme example of air being fully saturated at temperature of $30 \mathrm{C}$ and a total air pressure of $500 \mathrm{mb}$. The saturation vapor pressure is $e \approx 42 \mathrm{mb}$, and $h=0.084$. The value of $(\gamma-1)$ for dry air is 0.4 , while for moist air it is 0.3934 , for a percentage difference of less than $2 \%$. In other words, the variation of $\gamma$ with air pressure and relative humidity in the photoacoustic equation (1) is generally negligible, though of course one could easily take it into account since the requisite measurements to obtain it are available.

[16] The speed of sound in moist air is

$$
c=\sqrt{\gamma \frac{1000 R T}{29-11 h}}
$$

where $R$ is the universal gas constant and MKSA units are used [Bohn, 1988]. The denominator of equation (5) is the average molecular weight of moist air, and equation (4) arises from the water vapor molecules having one more degree of rotational freedom than the main diatomic constituents of air. The density of moist air, $\rho$, is

$$
\rho=\frac{P(m b)}{R T}(2.9-1.1 h) \text {. }
$$

The resonator quality factor can be expressed as

$$
\begin{aligned}
\frac{1}{Q} & \equiv \frac{\text { Acoustic Power Lost per Cycle }}{\text { Energy Stored }}=\frac{1}{Q_{\text {transport }}}+\frac{1}{Q_{\text {loss }}} \\
& =\frac{\delta_{\eta}}{r}+(\gamma-1) \delta_{T}\left(\frac{2}{L}+\frac{1}{r}\right)+\frac{1}{Q_{\text {loss }}},
\end{aligned}
$$

where acoustic boundary layer losses occur in the thermal and boundary layer thickness

$$
\delta_{\eta}=\sqrt{\frac{\eta}{\rho \pi f_{0}}}, \quad \delta_{T}=\sqrt{\frac{\kappa}{c_{p} \rho \pi f_{0}}}=\frac{\delta_{\eta}}{\sqrt{N_{p r}}}
$$

respectively, and $r=0.838 \mathrm{~cm}$ is the resonator radius, and $L=22.5 \mathrm{~cm}$ is the resonator length. The term involving resonator length is due to dissipation of thermal energy in the boundary layer at the ends of the resonator. No viscous energy is dissipated here. A similar expression applies to radial wave acoustical resonators [Kamm, 1976]. In equation (8), $\eta$ is the viscosity of the moist air, $\kappa$ is the thermal conductivity, $c_{p}$ is the isobaric heat capacity per unit mass, and $N_{p r}=\eta c_{p} / \kappa$ is the Prandtl number. The Prandtl number of dry air at standard conditions is approximately 0.7 . Other fractional losses in equation (7) might include microphone flexing due to its compliance, bulk acoustic losses in the gas mixture, and possibly other fluid dynamical motions of the gas such as vortex generation at the relatively sharp corners in the resonator section that occur where the resonator takes a perpendicular corner [Arnott et al., 2003a, 2005a]. In general, the other fractional losses in the bulk of the gas [Johnson et al., 1981] are due to free-space viscous and thermal damping and are small compared to the losses of fluid kinetic energy associated with the viscous boundary layer and fluid potential energy associated with the thermal boundary layer at the resonator wall, as the Q is a relatively modest value of around 73.

[17] The resonator quality factor associated with transport losses of thermal conduction and viscosity can be expressed as

$$
Q_{\text {transport }}=\sqrt{\frac{\pi f_{0} P(m b)(2.9-1.1 h)}{R T \eta}} r \frac{\sqrt{N_{p r}}}{\sqrt{N_{p r}}+\gamma-1},
$$

neglecting the relatively small term in equation (7) associate with the resonator length. The resonator is operated in an acoustical mode such that one full acoustic wavelength is spanned by the resonator length $L \approx$ $22.4 \mathrm{~cm}$. For example, the measured value in equation (7) is $Q \approx 73$, with calculated $Q_{\text {transport }}=98$ and inferred $Q_{\text {loss }}=300$ for one atmosphere pressure and $20 \mathrm{C}$. The condition for resonance can be approximated roughly by considering wave propagation in a lossy resonator [Arnott et al., 1996], and taking the real part of the complex propagation constant times the resonator length equal to $2 \pi$. This approach assumes that the boundary conditions at the resonator ends are that the acoustic velocity goes to zero. However, because of dissipation of acoustic potential energy at the resonator terminations in the thermal boundary layers at the microphone and piezoelectric transducer, this boundary condition is only approximate. This effect is small for the resonator discussed here. The resonance frequency can be expressed in terms of the sound speed, quality factor, and resonator length as

$$
f_{0}=\frac{c}{L}\left[1-\frac{1}{2 Q_{\text {transport }}}\right]
$$

assuming that the frequency shift is due entirely to wall absorption [Johnson et al., 1981]. A lossless acoustical resonator would have resonance frequency $f_{0}=c / L$.

[18] Equations (9) and (10) show that the primary variation of the resonator quality factor and resonance 
frequency scales as the square root of the ambient pressure,

$$
Q \propto \sqrt{P} .
$$

The temperature for the measurement is actually the instrument temperature rather than the ambient temperature of the outside air, so temperature variations are less of an issue than pressure variations. Relative humidity changes will have a secondary effect on these resonator parameters as the aircraft cabin is heated.

[19] The model for photoacoustic signals contains two components,

$$
\beta_{a b s}(T, P)=\beta_{a b s}^{\text {Background }}\left(T_{b g}, P_{b g}\right) \frac{P T_{b g}}{P_{b g} T}+\beta_{a b s}^{\text {particle }}(T, P),
$$

where the background measurement is made at pressure $P_{b g}$, and temperature $T_{b g}$ when the instrument samples filtered air. This model assumes, for good reason, that the background signals are due to the laser beam making sound from a stray reflection rather than the background being associated with a pressure- and temperature-independent electronic bleed. Tests made with the instrument on the ground verify this model. The air parcel density is corrected to first order in the first term of equation (12), though drastic changes in RH over short time spans could have a second-order density effect. The best way to deal with the background is to align the laser beam so that this term is negligible, though occasional background measurements are advisable to confirm that this condition holds true. If this is not possible, then the background signal, measured at pressure $P_{b g}$, and temperature $T_{b g}$ must be computed at other pressures and temperatures with equation (12).

[20] The acoustical resonator is periodically calibrated for determination of $\mathrm{Q}$ and resonance frequency by use of the piezoelectric transducer. The microphone pressure as a function of the piezoelectric transducer velocity, $v_{0}$, and displacement $D_{0}=i v_{0} / \omega$ can be expressed as

$$
P_{0}=v_{0} \frac{\rho \omega}{k \sin (k L)}=-i D_{0} \frac{\rho \omega^{2}}{k \sin (k L)},
$$

where $k$ is the complex propagation constant, given by

$$
k=\frac{\omega}{c}\left(1+\frac{1}{2 Q}+\frac{i}{2 Q}\right) .
$$

Here $Q$ can be obtained directly from equation (7), or from measurements when the frequency is restricted to the near vicinity of a resonance. Expansion of the acoustic pressure in equation (13) about the resonance condition $\operatorname{Real}(k L)=2 \pi$ gives the familiar frequency dependence

$$
P_{0}(f)=v_{0} \frac{\rho c Q}{\pi} \frac{1}{\frac{2 Q\left(f-f_{0}\right)}{f_{0}}+i}=-i D_{0} 2 \rho c Q \frac{1}{\frac{2 Q\left(f-f_{0}\right)}{f_{0}}+i} .
$$

In practice calibrations with the acoustic transducer are fit to the magnitude of the acoustic response expressed simply as [Arnott et al., 1995]

$$
\left|P_{0}(f)\right|^{2}=\frac{P_{0}^{2}}{1+\left(\frac{2 Q\left(f-f_{0}\right)}{f_{0}}\right)}
$$

where $P_{o}$ is the peak pressure at resonance where $f=f_{0}$, and is given by

$$
P_{0}=\frac{\rho c v_{0}}{\pi} Q
$$

The quality factor $Q$ and the resonance frequency obtained from the fit of equation (16) to measurements are used directly in the photoacoustic equation, equation (1). The resonance frequency can be obtained with an accuracy and precision better than 1 part in 1500 , and the quality factor as 1 part in 150 . The peak acoustic pressure at resonance given in equation (16) is useful for evaluating the microphone calibration stability as well as investigating the microphone response as a function of ambient pressure, temperature, and relative humidity.

[21] Figure 1 shows the acoustical resonator properties during a typical flight from the Department of Energy Atmospheric Radiation Program Intensive Operational Period (DOE-ARM IOP) on 27 May 2003. More details about the nature of this IOP will be given in the next section, though for current purposes it suffices to mention that this flight traversed an altitude range of around $500 \mathrm{mb}$, and various layers having different relative humidity were encountered. The relatively weak dependence given in equation (11), and periodic acoustic calibrations appear sufficient to keep the resonator in calibration during flight. Figure 1a shows the peak acoustic pressure obtained from the fit of equation (16). The quality factor and resonance frequency are shown in Figures $1 \mathrm{~b}$ and $1 \mathrm{~d}$, respectively. Note in Figure $1 \mathrm{~b}$ the relatively systematic dependence of the quality factor with altitude, appropriate for the simple pressure dependence given in equation (11). The resonance frequency in Figure 1d has a dependence both on ambient pressure, through the dispersion associated with the boundary layer dissipation, as well as on the instrument temperature and relative humidity through the sound speed given by equation (5), resulting in the spread of values shown in Figure $1 \mathrm{~d}$. The resonator time constant is a measure of the time it takes to build up a standing wave in the acoustical resonator, and the time it takes for such a wave to decay, and is proportional to the ratio of the resonator quality factor and resonance frequency. It is shown in Figure 1c, and is seen to be less than $50 \mathrm{~ms}$. An excessively large time constant would interfere with the ability to determine the vertical profile of light absorption, but this value is quite modest. The flow time constant for changing the sample air in the instrument is $1 \mathrm{~s}$, and so dominates the time response of the instrument. A refinement of the operating procedure would be to use the measured values of RH, ambient temperature, and ambient pressure to dictate how often an acoustic calibration should be accomplished. For example, it would be best to calibrate more often during spiral ascents or descents, and less often during level flight. Overall it seems 

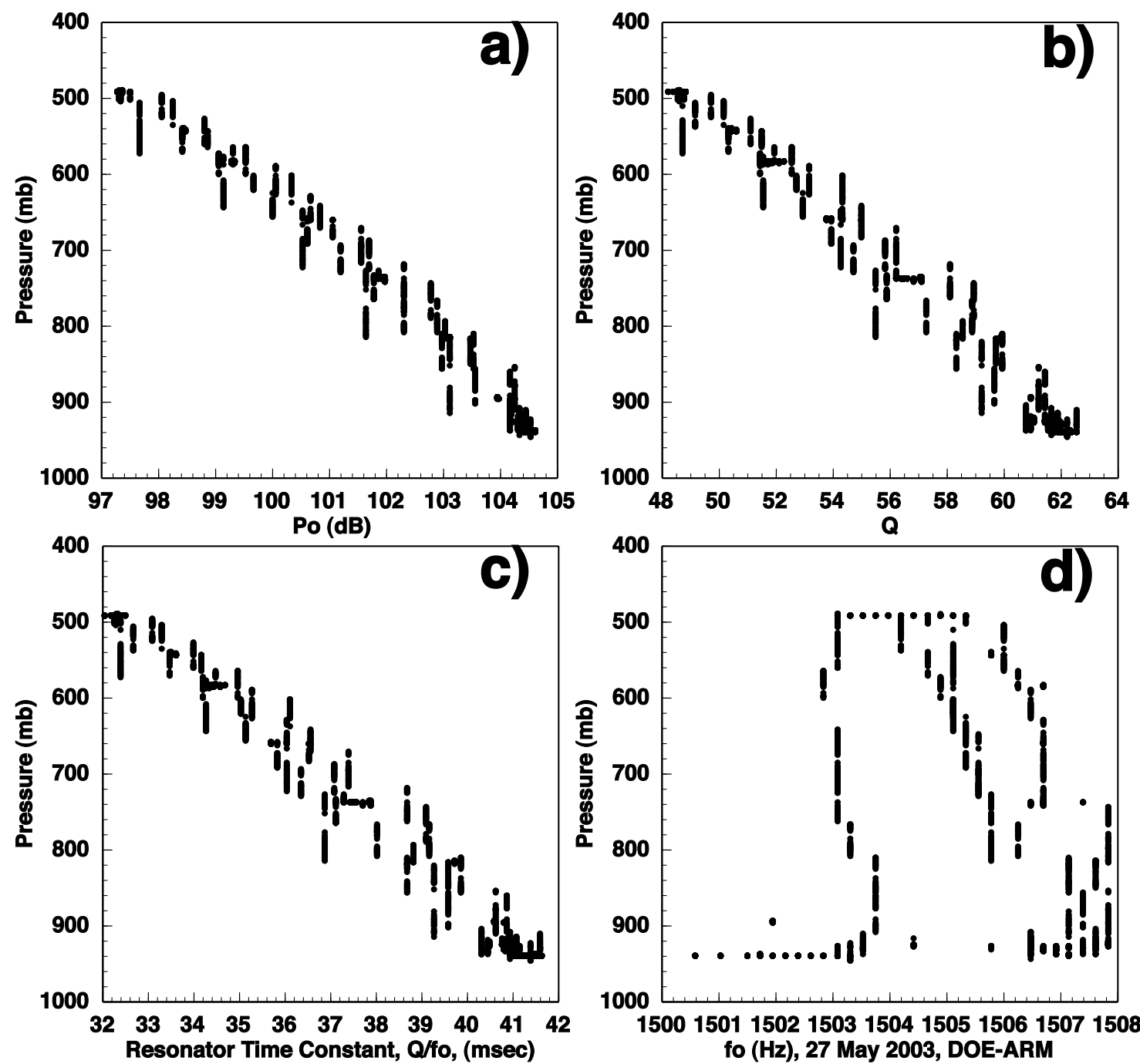

Figure 1. Variation of the acoustical resonator with ambient pressure. (a) Peak pressure during the acoustical calibration accomplished with the piezoelectric transducer and microphone, (b) the quality factor, (c) the resonator time constant, and (d) the resonance frequency. Variations in the ambient temperature and RH during the flight cause the multivaluedness.

best to do the acoustic calibration as often as needed rather than to rely on the detailed model for the quality factor and resonance frequency to interpolate between measurements, as the acoustic calibration takes only about $2 \mathrm{~s}$.

[22] The combination of equations (7) and (11) give a model derived fit for the dependence of the quality factor on ambient pressure. Figure 2 shows measurements and the model fit for simulated measurements aloft accomplished by using a valve at the instrument inlet to reduce pressure inside of the instrument when the sample pump is operated. This model fits the measurements quite well, and could be used to verify measurements aloft.

[23] Figures 3 and 4 show a comparison of the approximate (equation (15)) and full models (equation (13)) for the frequency response of the acoustical resonator. The purpose of showing Figure 3 and 4 is to evaluate the appropriateness of using the approximate model, given that it is used in practice to obtain the resonance frequency, quality factor, and peak acoustic pressure. Figure 3 shows that the approximate model captures the magnitude of the frequency response. The phase difference between the piezoelectric source used for this acoustic calibration and the microphone response is shown in Figure 4. The phase error is within around 1 degree for the approximate model. It should be noted that in practice, phase sensitive detection is used to obtain light absorption from the photoacoustic equation, equation (1). The complex ratio of microphone pressure and laser power is calculated, and the real part of this ratio is used in equation (1). In other words, the part of the microphone pressure in phase with the laser power modulation is due to light absorption and not random noise. The variation of the phase with resonant frequency is important to understand since acoustic calibration is obtained at fixed intervals, and the phase variation could disrupt phase sensitive detection if not accomplished often enough.

[24] Figure 5 shows a comparison of measurements of the peak acoustic pressure at resonance compared with model results from use of equation (17), as a function of ambient pressure in the range from $400 \mathrm{mb}$ to $1000 \mathrm{mb}$. The ambient pressure was adjusted over the range $400 \mathrm{mb}$ to $1000 \mathrm{mb}$ 


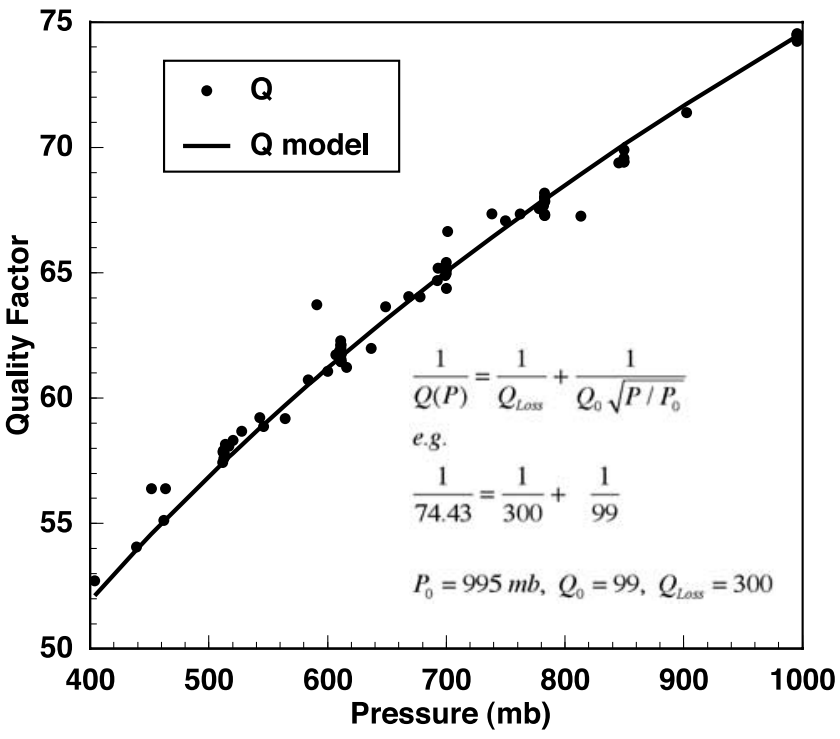

Figure 2. Resonator quality factor as a function of ambient pressure obtained with a valve on the inlet to simulate flight conditions.

with use of a valve over the input to reduce the pressure inside of the instrument when the pump is turned on. The linear behavior of the measured peak acoustic pressure shows that the microphone calibration does not vary with ambient pressure, and is an important result that shows that light absorption measurements aloft with the microphone are accurate. It also shows that the method used for the microphone static pressure equilibration works well. The potential issue is that reduction of the static pressure might pull the pliable microphone membrane away from the fixed plate that forms the second plate of the capacitance microphone, and thereby change the microphone calibration. The agreement of measured and model results shown in Figure 5

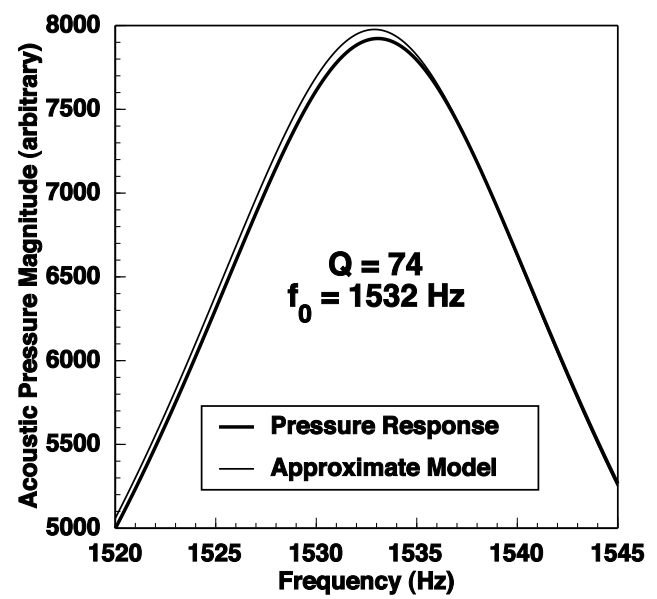

Figure 3. Magnitude of the acoustic pressure at the microphone, using the piezoelectric transducer as a calibration source, as a function of frequency. The thin curve is from the approximate model in equation (15), and the thick curve is from the full form of equation (13).

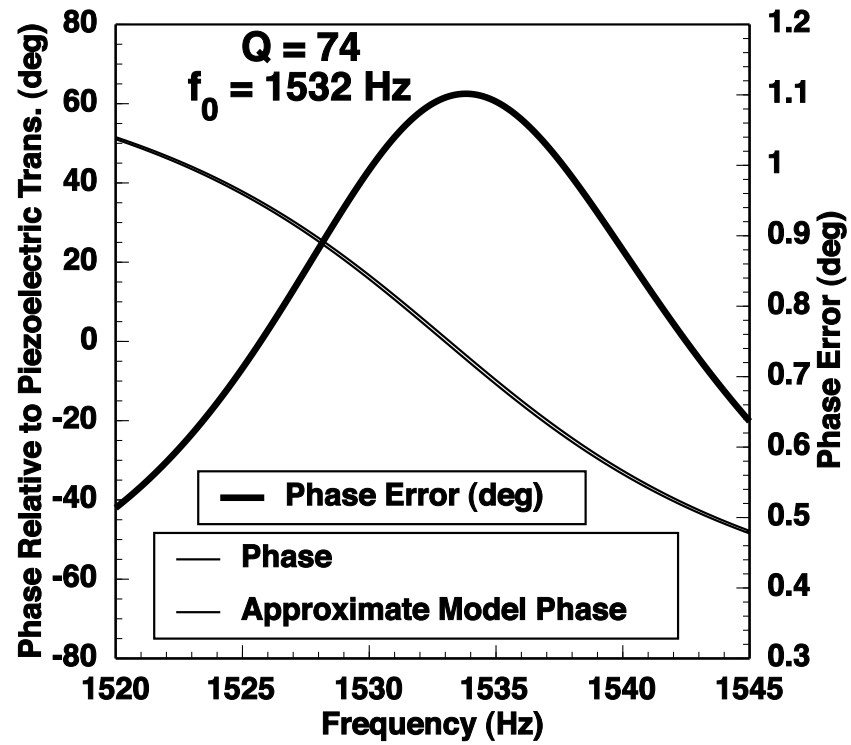

Figure 4. Phase of the acoustic pressure at the microphone relative to the piezoelectric transducer as a function of frequency. The thin curve is from the approximate model, and the thick curve is from the full form. The phase shows a monotonic reduction with frequency. The phase error from use of the approximate model is shown relative to the axis on the right and is small.

shows that this effect does not happen given that the instrument was designed to avoid this issue. A more subtle point is that the microphone membrane damping could also be changed when the composition of the air (that is, the air density, as the air is intentionally dried to avoid humidity issues that might affect the microphone preamplifier) on the backside of the microphone changes, and this could affect the frequency response of the microphone and its noise characteristics. The piezoelectric velocity amplitude and

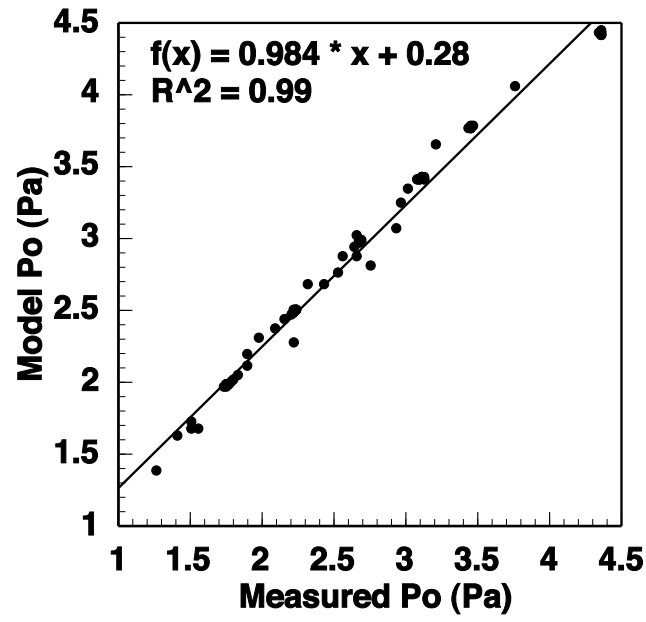

Figure 5. Measured and modeled peak acoustic pressure during calibration with the piezoelectric transducer as a function of ambient pressure. The smallest and largest values were obtained at ambient pressures of $400 \mathrm{mb}$ and $1000 \mathrm{mb}$, respectively. 
displacement are obtained by fit of equation (17) to measurement, and are $v_{0}=459 \mu \mathrm{m} / \mathrm{s}$ and $D_{0}=47.8 \mathrm{~nm}$.

[25] In summary, the acoustical performance of the resonant photoacoustic instrument is adequate and characterized well enough for accurate measurements of the aerosol light absorption coefficient aloft. The instrument was housed in a standard 19" equipment rack for these measurements and the rack space was around $30^{\prime \prime}$ or $76 \mathrm{~cm}$. The power requirement, excluding the community pump that was used for a number of instruments, was $100 \mathrm{~W}$, and the instrument weight was $150 \mathrm{lbs}$, or around $68 \mathrm{~kg}$.

\section{Photoacoustic Measurements of Aerosol Light Absorption Aloft}

[26] Examples are given in this section for measurements of aerosol light absorption aloft during several field campaigns. Comparisons will be made with measurements made with a modified Particle Soot Absorption Photometer (PSAP) originally manufactured by Radiance Research. A description of the modified PSAP and its calibration will be presented first, and measurements of smoke light absorption from long- and short-range transport of aerosols from fires will be provided in the following subsections.

\subsection{Modified Three-Wavelength Particle Soot Absorption Photometer}

[27] The original PSAP operates at $550 \mathrm{~nm}$. Measurements require knowledge of the spot size on the filter where particles are deposited and where the light source shines through the filter to the optical detector, and of the sample flow rate to determine the concentration of aerosol light absorption cross section. Particles deposited in the filter reduce the optical transmissivity of the filter, and it is this incremental change of transmissivity that is related to aerosol light absorption. Particles that scatter light also cause a reduction in filter transmissivity, though not through light absorption, but because these particles increase the light reflected by the filter-particle combination, and reduce the light transmission. The scattering effect is typically small, amounting to $2 \%$ of the scattered light by particles needing to be subtracted from the PSAP signal to correct for it, at least for the original PSAP [Bond et al., 1999]. This correction can be a substantial fraction of the PSAP signal when the single scattering albedo is close to unity, or equivalently when the aerosol composition is such that scattering dominates absorption. The manufacturer also applies a filter-loading correction function to the data to take into account the reduction of the filter multiple-scattering enhancement factor as the filter loads up with particles. This is analogous to the factor derived recently for the Aethalometer filter sampler [Arnott et al., 2005b]. The airflow through the PSAP takes sample air first through the sample filter where particles are deposited, and next through the reference filter that is used to normalize the PSAP optical source power. The air stream is first dried before measurement with the PSAP as a caution against optical effects associated with water vapor absorption by the backing of the filter and by particles already on the filter [Arnott et al., 2003b]. The original PSAP has been used previously to measure aerosol light absorption while sampling aloft from meteorological aircraft [Anderson et al., 2003].
[28] The modified PSAP operates at three nominal wavelengths $(467 \mathrm{~nm}, 530 \mathrm{~nm}$, and $660 \mathrm{~nm})$ provided by LED sources [Virkkula et al., 2005]. This instrument uses the same filter sampling system as the original PSAP though the detection electronics and optical configuration have been modified. The first model of the modified PSAP was evaluated and calibrated during the Reno Aerosol Optics Study (RAOS) [Sheridan et al., 2005; Virkkula et al., 2005], though subsequent modifications were applied to homogenize the light source in the time between RAOS and the aircraft campaigns discussed here. While it is not known for certain that the RAOS calibration of the modified PSAP also applies to the instrument used in the aircraft campaigns, the main results of the RAOS calibration are employed here to provide values for the PSAP consistent with its most recently completed calibration. The original PSAP calibration [Bond et al., 1999] applied to the light absorption value at $660 \mathrm{~nm}$ was shown to give numbers too large by a factor of 1.26 for the RAOS data set [Sheridan et al., 2005], and a more sophisticated data processing algorithm that takes into account both the particle scattering coefficient and single scattering albedo was developed [Virkkula et al., 2005]. The RAOS data set also showed that for aerosol single scattering albedos greater than about 0.8 the $660 \mathrm{~nm}$ wavelength calibration made by first applying the original calibration, and then division by the factor 1.26 was reasonable. This is the approach taken here to derive PSAP aerosol light absorption coefficients at $660 \mathrm{~nm}$ to compare with photoacoustic values at $676 \mathrm{~nm}$. The scattering correction was determined, when possible, from interpolations of the aerosol scattering coefficients at $550 \mathrm{~nm}$ and $700 \mathrm{~nm}$ made with the TSI nephelometer. Cases where scattering corrections are unavailable are clearly distinguished in the following sections.

\subsection{Aerosol Light Absorption by Smoke Transported From Siberian Forest Fires to North Central Oklahoma Observed Aloft During the DOE-ARM IOP}

[29] An IOP (Intensive Observational Period) was conducted at the Department of Energy's Atmospheric Radiation Measurement (ARM) Southern Great Plains Site in north central Oklahoma, in May 2003. The goal of this IOP was to gain improved understanding and model-based representation of aerosol radiative influences. The IOP used ground and airborne measurements of aerosol absorption, scattering, and extinction over the ARM SGP site to characterize the routine ARM aerosol measurements, and to help resolve differences between measurements and models of diffuse irradiance at the surface. More information about the IOP, and about the DOE-ARM program in general can be found at http://www.arm.gov. The aerosol IOP was conducted between 5 and 31 May 2003 over the ARM SGP site. There were a total of 16 science flights, for a total of 60.6 flight hours, conducted with the CIRPAS Twin Otter aircraft on 15 days during this period. Most of the Twin Otter flights were conducted under clear or partly cloudy skies to assess aerosol impacts on solar radiation. Several new and/or upgraded instruments were deployed over the ARM SGP for the first time during this mission. Examples of the new instruments include a cavity ringdown cell (NASA Ames) that measured aerosol extinction and the photoacoustic instrument that is the subject of this 


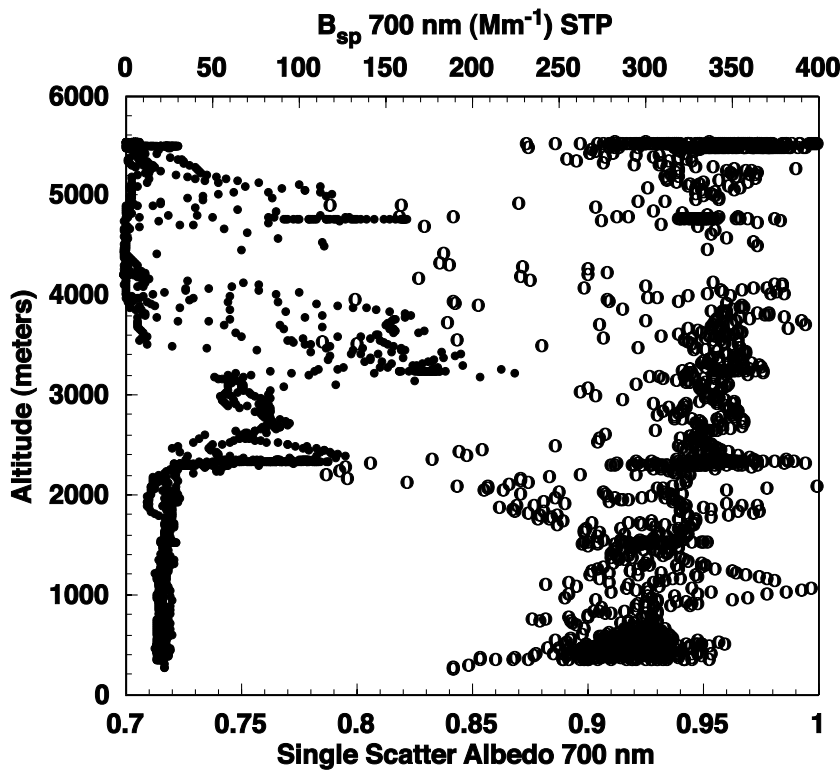

Figure 6. Smoke aerosol layers from Siberia observed on 27 May 2003 at the DOE-ARM site in north central Oklahoma. Open circles refer to single scatter albedo at $700 \mathrm{~nm}$ obtained from use of the University of Washington three-wavelength PSAP and three-wavelength nephelometer. Solid circles and the top axis indicate aerosol light scattering coefficient computed for an air parcel having a dry density at 273 Kelvin and $1013.25 \mathrm{mb}$ Note the relatively well mixed boundary layer below $2.2 \mathrm{~km}$ and the layers above.

paper. A more comprehensive overview of the IOP has been prepared [Ferrare et al., 2006], and a thorough analysis of the intercomparison of aerosol light absorption measurements aloft by the PSAP, difference of extinction and scattering, and photoacoustic measurements for flight legs through the entire IOP is available [Strawa et al., 2006].

[30] Aerosol optical properties aloft have been reported previously using this Twin Otter aircraft [Wang et al., 2002]. This unpressurized aircraft has a community inlet formed by an inlet tube of diameter around $10 \mathrm{~cm}$ that protrudes from the fuselage above the pilots cabin and forward of the aircraft. The inlet is equipped with an attachment to slow the flow of sample air down the tube. Sample air is obtained from a series of flush-mounted ports veering off at an angle of approximately 45 degrees from the incoming air. A flow damper is attached to the back of this tube to maintain a linear speed of $7 \mathrm{~m} / \mathrm{s}$ for the sample air coming down the tube. It is important to note that the sample air in the community inlet is at a pressure above ambient as a result of the flow damper, so that instrument leaks are less of a concern than would be experienced for use of pressurized aircraft [Anderson et $a l ., 2003]$. The photoacoustic instrument was housed in the rear of the aircraft approximately $2.5 \mathrm{~m}$ away from its sample port on the community inlet, and was connected to the inlet with nominal $6 \mathrm{~mm}$ ID conductive tubing. The flow rate down the sample line tubing was 8 LPM, and 1 LPM was picked off and sent to the photoacoustic instru- ment. Flow rates were determined by the use of critical orifices. It should be noted that ground-based characterization of the inlet was accomplished through use of a blower to deliver dried ammonium sulfate aerosol prepared as during the Reno Aerosol Optics Study [Sheridan et al., 2005]. A TSI 3563 nephelometer was attached to the community inlet with a very short sample line of around $40 \mathrm{~cm}$ length, and another instrument of the same type was used to sample from the sample line used for the photoacoustic instrument. When operated at the flow rate used for the photoacoustic instrument the difference in scattering measurement was less than $5 \%$ for these two nephelometers.

[31] As will be discussed further below, the photoacoustic instrument had higher noise when the aircraft was close to the ground and was experiencing turbulent conditions, likely as a result of pressure fluctuations at the inlet of the tube to the aircraft that propagated downstream to the photoacoustic instrument. The instrument worked best at altitudes above the boundary layer. Even though these were likely low-frequency pressure fluctuations outside of the operating frequency of the photoacoustic instrument at $1500 \mathrm{~Hz}$, they did cause the automatic ranging microphone preamplifier to overload at normal gains of 100 to 200, and to run at times with gain as low as 10 . Instrument noise is dominated by acoustic and microphone noise when the preamplifier is operated at or above

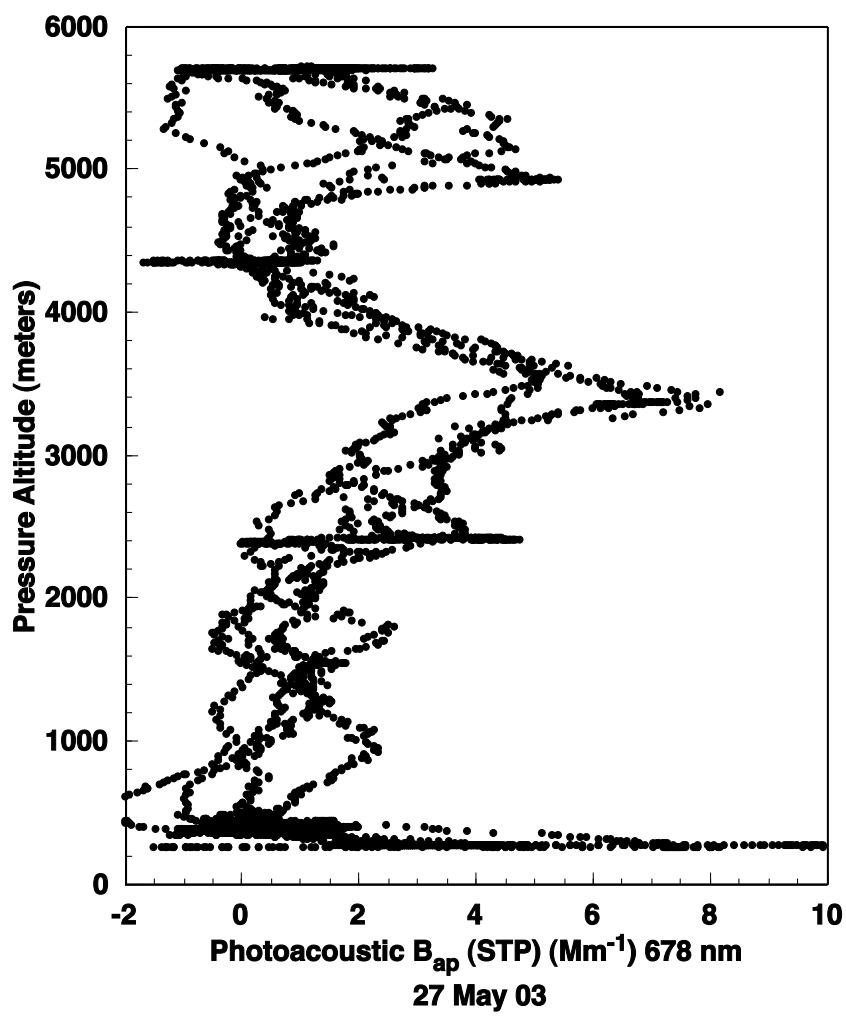

Figure 7. Photoacoustic measurement of aerosol light absorption at $676 \mathrm{~nm}$ for the layered case shown also in Figure 6. Aerosol light absorption was computed for an air parcel at standard conditions, same as in Figure 6. Note the distinct layer between 3 and $4 \mathrm{~km}$ and a more diffuse layer above, separated by a clean layer. 

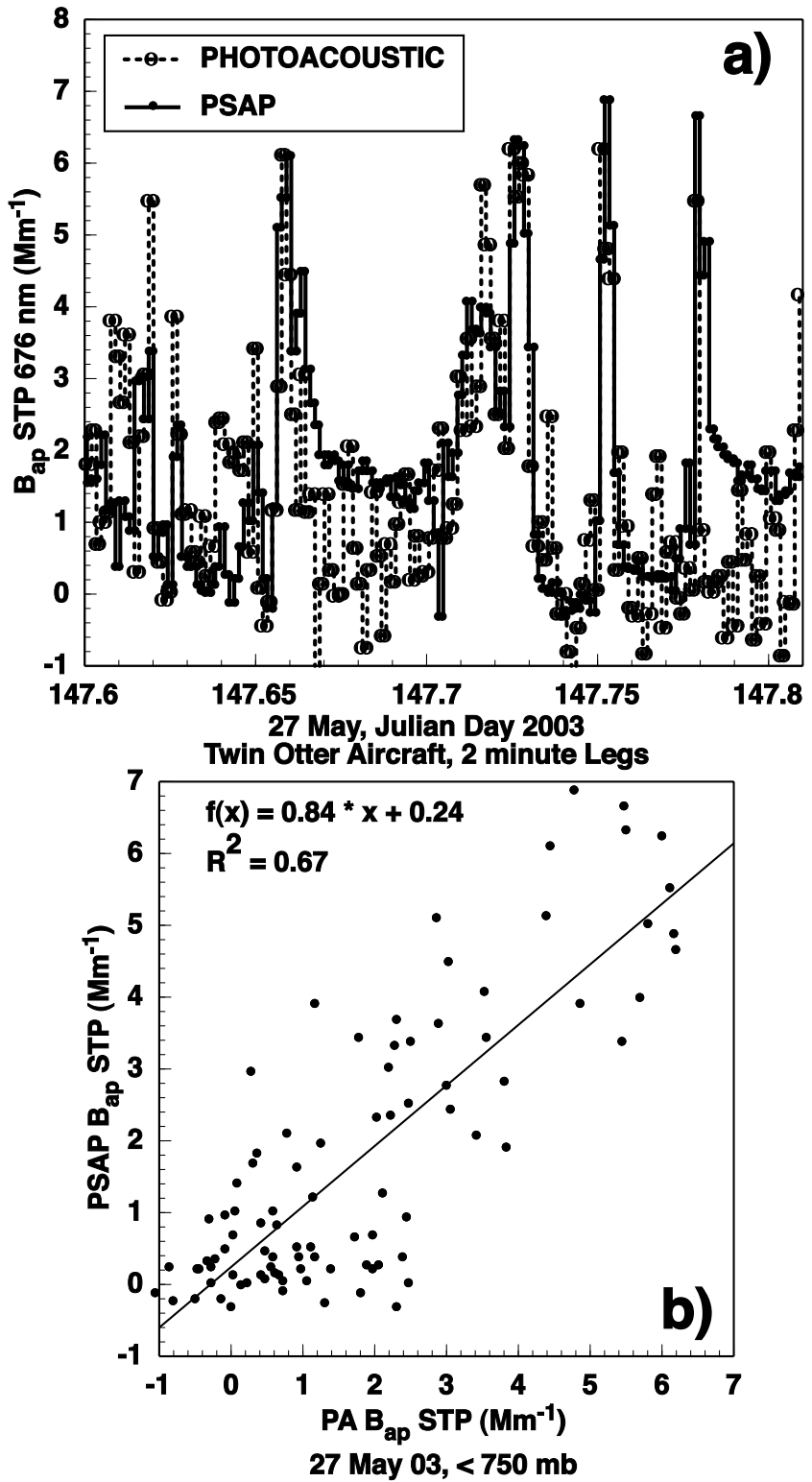

Figure 8. (a) Time series of photoacoustic and PSAP aerosol light absorption for an air parcel at standard conditions for the case also shown in Figure 6. The PSAP values were calibrated using the results of the Reno Aerosol Optics Study. Note generally good agreement for the layers and more discrepancy when the aircraft was closest to the ground as in the relative minima before 147.7 and in the vicinity of 147.8. (b) Scatterplot for a data subset of the time series shown in Figure 8a. The subset was chosen from all data where the ambient pressure was below $750 \mathrm{mb}$.

a gain of 100 , and at a gain of 10 the noise inherent in the data acquisition system dominates. An acoustic resistor was placed at the inlet of the photoacoustic instrument to mitigate and dampen the ambient pressure fluctuations observed in the boundary layer. This resistor was simply a brass tube of $2 \mathrm{~mm}$ ID and length $4 \mathrm{~cm}$. Pressure fluctuations are dampened by this resistor owing to viscous dampening effects in the acoustic boundary layer. Finally, in aircraft operations undertaken in programs after those reported here, a $300 \mathrm{~Hz}$ electronic high pass filter was applied directly to the microphone signal at the microphone power supply, and the programmable preamplifier was operated with a $12 \mathrm{~dB} /$ octave high pass filter with cut point set at $1 \mathrm{kHz}$. These electronic measures were sufficient to make photoacoustic light absorption data quality equivalently good at all levels of the atmosphere even without the use of an acoustic resistor. The air stream was dried below an RH of $40 \%$ before the TSI Model 3563 nephelometer received the sample air. The PSAP and nephelometer combination was used on the Twin Otter in the same manner as it was previous used on the National Center for Atmospheric Research C-130 aircraft during ACE-Asia [Anderson et al., 2003].

[32] Elevated aerosol extinction was observed over the ARM SGP site in layers above the atmospheric boundary layer, 2-5 km above the surface. On 27 May 2003, and other days near this time, these layers were the result of the transport of smoke from intense Siberian fires a continent and ocean away from Oklahoma [Damoah et al., 2004]. This smoke in fact circumnavigated the globe in about 17 days. It was also perhaps the most interesting event recorded during the aerosol IOP, and it is fitting to use it here as a first published example of photoacoustic aerosol light absorption measurements aloft from meteorological aircraft. These sorts of layers are especially important to understand as they typically are unrelated to ground-based measurements, and yet can have a significant climate impact. Figure 6 introduces the aerosol optics associated with these layers. The "potential" aerosol scattering coefficient at $700 \mathrm{~nm}$ as measured with the TSI nephelometer and processed to be relevant for an air parcel at temperature of $273.15 \mathrm{~K}$ and a pressure of $1013.25 \mathrm{mb}$ is shown as a function of altitude. Note the distinct layer between 2 and $4 \mathrm{~km}$, the clean layer between $4 \mathrm{~km}$ and $4.8 \mathrm{~km}$, and finally another layer above $4.8 \mathrm{~km}$. Note also that the atmosphere seems to be well mixed below $2 \mathrm{~km}$, and that in situ ground-based measurements of aerosol scattering coefficients would not give any information about the layers above. Figure 6 also shows the aerosol single scattering albedo at $700 \mathrm{~nm}$ at computed from the ratio of particle scattering to extinction coefficients. Nephelometer scattering and PSAP absorption at $660 \mathrm{~nm}$ (extrapolated to $700 \mathrm{~nm}$ by multiplication with the factor 660/700 thus assuming an inverse wavelength dependence for light absorption) were summed to obtain extinction. Note that the first layer above $2 \mathrm{~km}$ has a single scattering albedo of around 0.95 though with some fluctuations up to 0.99 .

[33] Photoacoustic measurements of aerosol light absorption at $676 \mathrm{~nm}$ from the Twin Otter aircraft are shown as a function of altitude in Figure 7. Multiple passes through the same level were performed. Note the existence of the same layers observed in the scattering coefficient measurements shown in Figure 6, and the relatively clean layer between about $4 \mathrm{~km}$ and $4.8 \mathrm{~km}$. The higher levels near the surface were obtained when the aircraft was loitering near the ground or on the runway. Data were acquired every $3 \mathrm{~s}$ and a running average of 40 consecutive points was applied to the data shown in Figure 7 to smooth them. Figure 8a shows a time series of photoacoustic and PSAP aerosol light absorption measurements at $676 \mathrm{~nm}$ and $660 \mathrm{~nm}$, respec- 


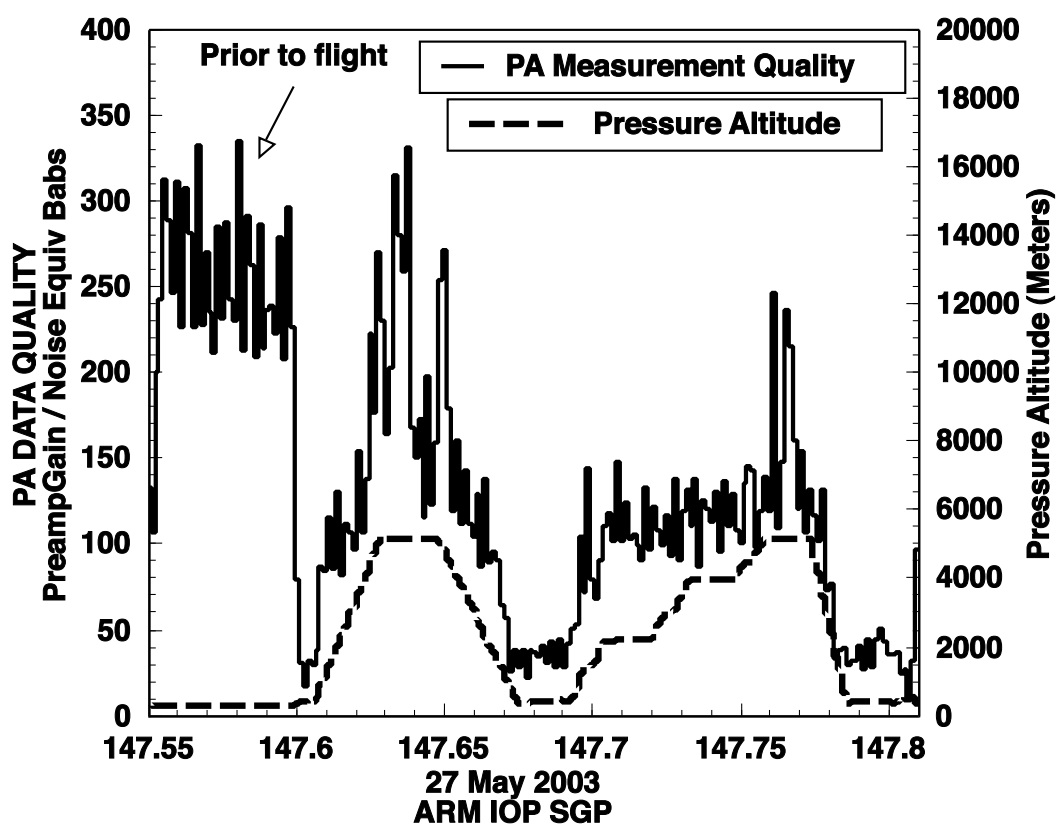

Figure 9. Time series of the photoacoustic data quality metric and its relationship with aircraft altitude. The aircraft was on the runway during the period before time 147.6. Note that data quality is highest when the aircraft was at its highest elevations and was lowest when the aircraft was near the ground. It is likely that turbulence in the lower levels degraded data quality, though in later efforts this effect was mitigated by use of an improved electronic high pass filter.

tively, that is another representation of the data in Figures 6 and 7. The two instruments tend to show agreement at peak values, associated with passage through the layers illustrated in Figure 6, though also show larger disagreement in the minima between Julian day 147.65 and 147.7. Yet in the minima before and after Julian day 147.75 better agreement is found.

[34] Figure 8b shows a scatterplot of a data subset from the time series in Figure 8a. The subset represents all data when the aircraft is at an altitude where the ambient pressure is below $750 \mathrm{mb}$, so that the data subset includes the layers illustrated in Figure 7, and it excludes data from near the surface where the photoacoustic data quality is less adequate, as described below. A linear regression was applied to these data and a modest correlation is indicated. The offset is relatively small, though is within the precision of the measurements. This scatterplot illustrates the comparison of photoacoustic and PSAP measurements of aerosol light absorption under low to modest aerosol amounts. The relative scatter is indicative of the current state of the measurement science and is considerably greater than typical for ground-based comparisons. By considering the data in the range from -1 to $1 \mathrm{Mm}^{-1}$, the uncertainty in the photoacoustic values is about $1 \mathrm{Mm}^{-1}$, and those of the PSAP are around $0.5 \mathrm{Mm}^{-1}$, though keep in mind that the PSAP has a significant response to scattering aerosol, and that imprecise subtraction of the scattering offset can give rise to an appearance of decent precision if some of the scattering influence remains present even after subtraction, and if the overall aerosol loading correlates with the black carbon fraction. The uncertainty in photoacoustic values scales inversely with laser power, so that current state of the science instruments employing three times the laser power that have been developed since this campaign have uncertainties around $0.4 \mathrm{Mm}^{-1}$ with $1 \mathrm{~s}$ integration time when operated in the laboratory, and should produce uncertainties less than $0.5 \mathrm{Mm}^{-1}$ when operated in the manner of the data illustrated in Figure 8b). At this point we can state that the instruments agree within $\pm 40 \%$ of each other when operated aloft though it is premature to state which instrument has actually delivered the "right answer" given that operation of measurement standards on the ground is more certain than when they are operated aloft.

[35] Figure 9 sheds light on perhaps the reason that this discrepancy of instrument comparison is found in the minima. A figure of merit for the photoacoustic measurements can be defined as the programmable preamplifier gain divided by the noise equivalent aerosol light absorption coefficient. The programmable preamplifier is constantly adjusted by the instrument software to keep the peak voltage close to 1 volt at the a/d card input. Massive pressure fluctuations in the boundary layer turbulence is thought to cause low-frequency pressure fluctuations as discussed earlier, and as a consequence, the need to run the preamp at lower gain. The noise equivalent aerosol light absorption coefficient is determined at every photoacoustic measurement of aerosol light absorption, and is computed as follows. The photoacoustic instrument operates at $1500 \mathrm{~Hz}$, and typically has a Q of around 70. The bandwidth associated with the acoustic resonance is around $22 \mathrm{~Hz}$. Each measurement of aerosol light absorption is accomplished by first acquiring $1 \mathrm{~s}$ of time domain microphone signal at a sampling rate of eleven times the resonant frequency. Then a complex Fourier transform is applied to this time domain signal, after a Hamming window is applied to it. The Fourier component at $1500 \mathrm{~Hz}$ is the light absorption signal, and the rest of the 


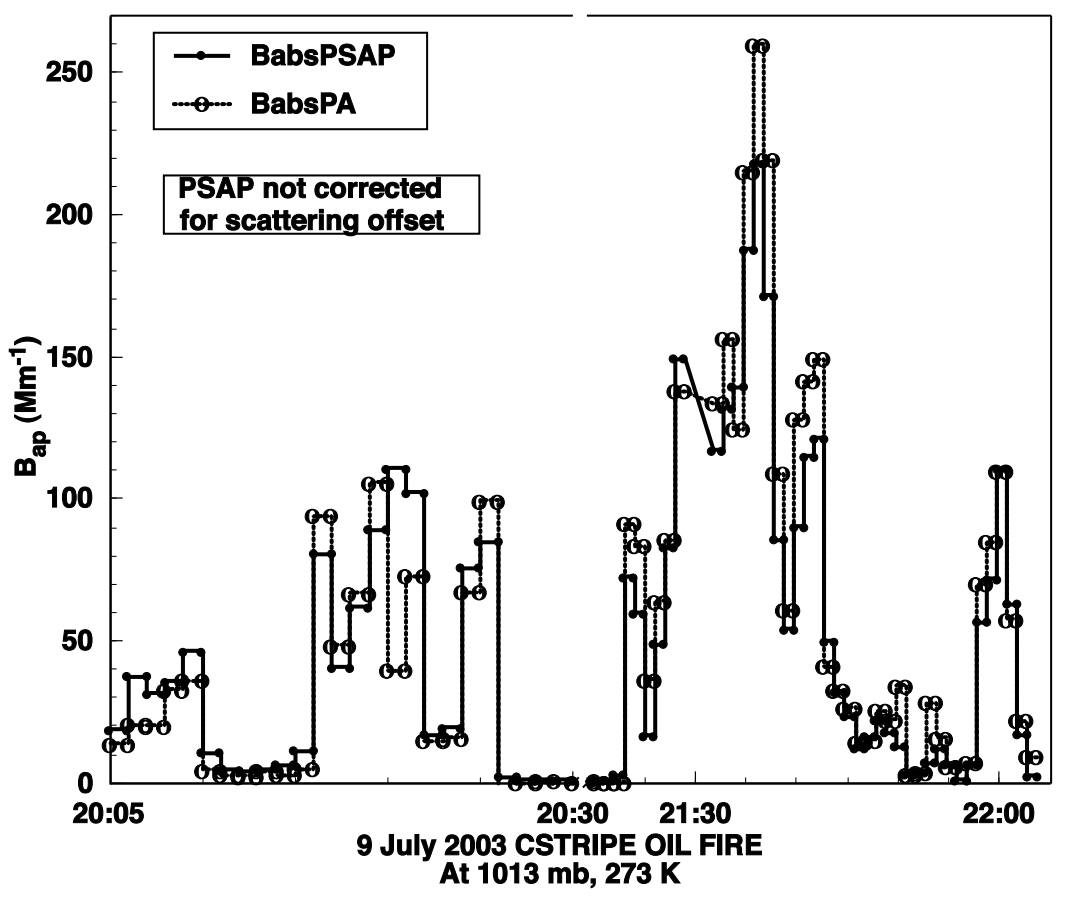

Figure 10. Time series of minute-averaged photoacoustic and PSAP filter-based aerosol light absorption for particles generated by an oil fire in Moss Landing, California. In-plume measurements were accomplished at an altitude of around $230 \mathrm{~m}$ above ground level, and the plume was very dark, indicating a low single scattering albedo. A filter change on the PSAP was accomplished at around 21:30. Note that the PSAP data were not corrected for scattering offset, though this correction for such a dark aerosol makes little effect.

acoustic energy within the band pass of the resonator is the resultant noise associated with actual acoustic sources of noise, and electronic noise of the remaining system from the microphone to the microphone power supply, and on to the programmable preamplifier and the a/d card in the computer. The magnitude of the Fourier spectrum, excluding the resonance peak and its shoulders, is first weighted by the inverse of the magnitude of the resonator response function given in equation 16 so that all spectral values have equal contribution to the average next applied to the spectrum. This noise equivalent pressure is then processed as if it were a pressure at the operating frequency, and a light absorption value is computed for it using equation (1). It has been demonstrated in many laboratory situations that the noise equivalent light absorption coefficient is a bounding value such that when filtered air is used in the instrument, and it is aligned well or zeroed, the time series of light absorption values have a random phase that gives values that eventually cover the entire range of \pm the noise equivalent light absorption coefficient. The photoacoustic data quality is highest when the instrument is in the aircraft on the ground, and by looking at the time series of the aircraft altitude also shown in Figure 9 as the dashed curve, it is apparent that photoacoustic data quality is lowest when the aircraft is closest to the ground.

[36] Now going back to the PSAP and photoacoustic comparison in Figure 8, the largest discrepancies in the minima happen at precisely these times, around Julian day 147.7 and 147.8, when the aircraft is closest to the ground.
It is probably expected that the measurements close to the ground would be relatively homogeneous on a well-mixed day in the atmospheric boundary layer if no strong local sources are present, and it is likely that the oscillations in the photoacoustic data at these times are due to the lower data

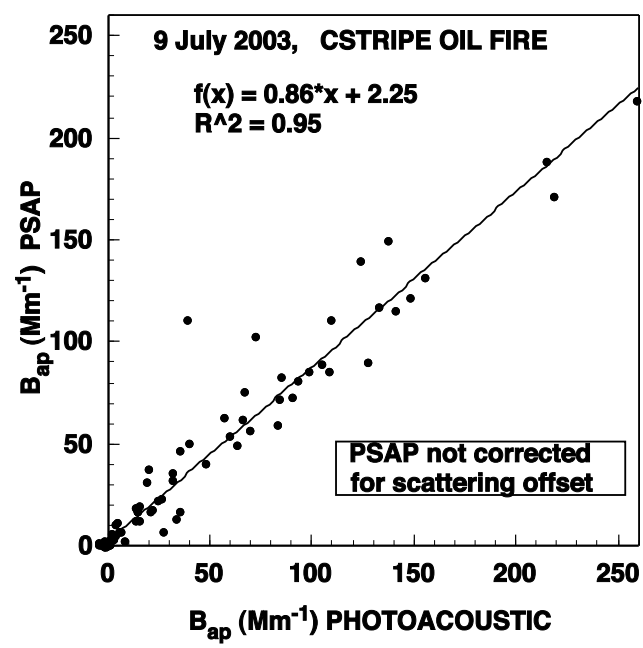

Figure 11. Scatterplot comparison of PSAP and photoacoustic aerosol light absorption measurements for the oil fire time series shown in Figure 10. Photoacoustic values are larger than PSAP values, as similarly noted during the low single scattering albedo measurements obtained during the Reno Aerosol Optics Study. 

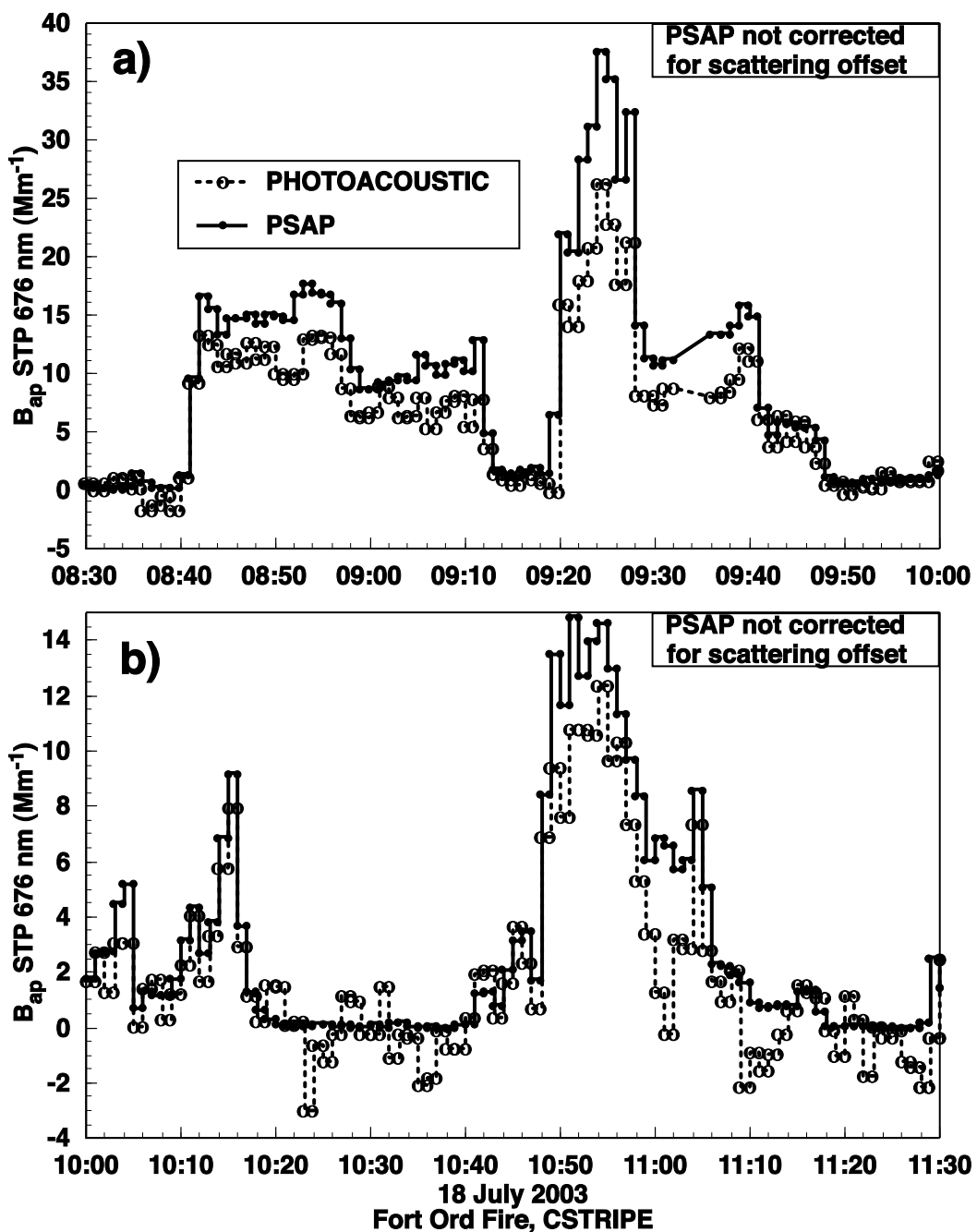

Figure 12. ( $\mathrm{a}$ and $\mathrm{b}$ ) Time series of minute-averaged photoacoustic and PSAP filter-based aerosol light absorption for particles generated by a wild fire at Fort Ord near Seaside, California. In-plume measurements were accomplished at an altitude above ground level to $400 \mathrm{~m}$, and the plume was very white, indicating a high single scattering albedo. Note that the PSAP data were not corrected for scattering offset and that this correction for such a "white" aerosol makes a large effect. The time range is broken up into two parts for clarity.

quality at these times. In defense of the photoacoustic measurements, later work after that reported here has demonstrated that much higher photoacoustic data quality can be obtained at all times by first directly applying a $300 \mathrm{~Hz}$ high pass filter to the microphone, and then using a $12 \mathrm{~dB} /$ octave high pass filter with a cut point at $1 \mathrm{kHz}$, and the acoustic resistor does not have to be used. Also, more laser power translates into greater photoacoustic sensitivity, and the laser power could be increased by a factor of 5 more than employed here before issues associated with particle heating become important.

\subsection{Aerosol Light Absorption From Local Fires} Observed Near Monterey, California, During the Coastal Stratocumulus Imposed Perturbation Experiments (CSTRIPE)

[37] CSTRIPE was a field experiment designed to quantify the effect aerosol has on the microphysics, precipitation and dynamics of marine stratocumulus (MSc). The CIRPAS Twin Otter aircraft was deployed in a three week mission off the coast of Monterey, California, in July 2003, 1 month after the end of the IOP in Oklahoma. The same photoacoustic instrument was used again on the Otter during this mission. A secondary objective of this study was to quantify black carbon emissions downwind of major sources such as large metropolitan areas, or unique targets of opportunity such as wildland fires. The Otter instrument package was changed between the ARM-IOP and C-STRIPE. For example, the emphasis shifted from heavy concentration on aerosol optics to an emphasis on aerosol chemistry. The TSI and Radiance research nephelometers were removed from the aircraft and were replaced with an Aerodyne mass spectrometer. However, the same PSAP instrument used during the ARM IOP was again employed during C-STRIPE. Sample air for the PSAP was treated with a diffusion dryer to reduce the $\mathrm{RH}$ to below $40 \%$. Two major smoke events 
FORT ORD FIRE, CSTRIPE, 18 July 2003
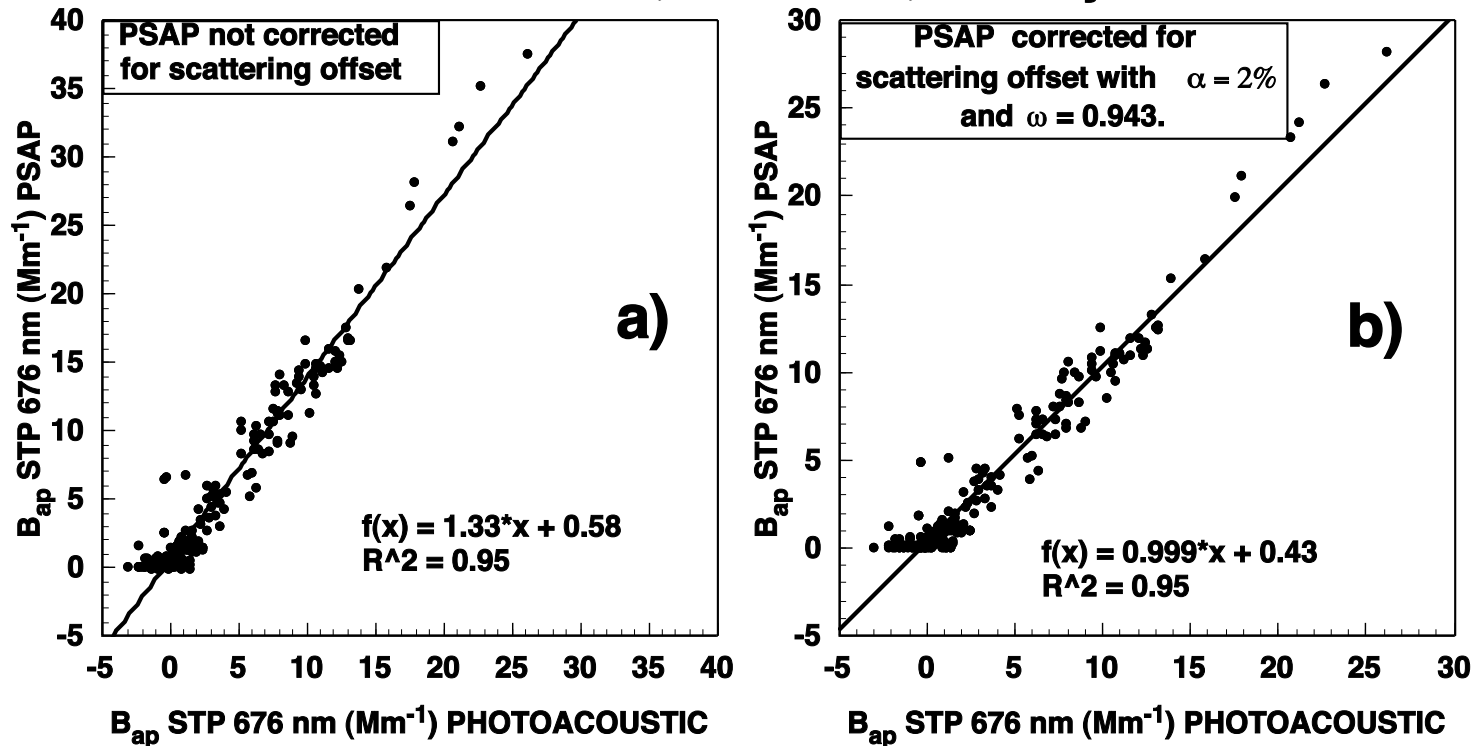

Figure 13. ( $a$ and b) Scatterplot comparison of aerosol light absorption measurements for the Fort Ord fire aerosol time series shown in Figure 12. In Figure 13a, uncorrected PSAP values are 1/3 larger than photoacoustic values, likely because of the effect of scattering aerosol on the PSAP measurements. For example, if $2 \%$ of the aerosol scattering coefficient is measured as apparent absorption by the PSAP, an aerosol single scattering albedo of 0.943 would give the observed slope of 1.33 shown above, assuming that a perfect slope is unity, as shown in Figure 13b. From the whiteness of the smoke to the visible eye it is likely that this single scattering albedo is reasonable.

occurred during CSTRIPE, and will be discussed in this subsection.

[38] The first event was a large oil fire in Moss Landing, California, located near Monterey. A Reuters News Service description of the fire is given here (Reuters News Service, 2003).

SAN FRANCISCO, July 8 (Reuters) - A fire broke late on Tuesday in an abandoned fuel tank at Duke Energy Corp.'s (nyse: DUK - news people) Moss Landing power plant on the California coast near Santa Cruz, the company said. A Duke spokesman said the fire had not affected the plant's generating capacity of 2,500 megawatts, roughly enough electricity to run 2.5 million California homes and businesses. "We had 19 obsolete fuel oil tanks on the site. We were dismantling the last of them when the contractor reported that residual fuel oil in one of the tanks ignited,' said Pat Mullen, a spokesman for Duke Energy. There were no injuries reported and the local fire department had contained the fire to the one tank, he said. The burning tank contained only residual oil, Mullen said, adding that the plant no longer burns oil since the generating units have all been upgraded to burn natural gas. The California power grid was operating earlier on Tuesday with ample supplies of electricity available, according to the state grid operator.

This fire produced copious black smoke that was clearly visible from the Otter's aircraft hangar in Marina, California.

[39] Figure 10 is a time series of an Otter flight through the oil smoke at an altitude of around $230 \mathrm{~m}$. If the oil burns as a rich kerosene lamp flame the aerosol single scatter albedo at $676 \mathrm{~nm}$ could be as low as 0.28 [Arnott et al., 2000; Sheridan et al., 2005]. Levels as high as $250 \mathrm{Mm}^{-1}$ were observed, though when out of the plume the background was very low as illustrated near 20:30. This time series is has an explicit 2 minute time average applied to both the PSAP and photoacoustic data. The PSAP data were not corrected for scattering offset though it should be very small in this case of dark aerosol. It is much more likely that the reduction of the filter multiple scattering enhancement factor not currently well understood for the PSAP when such dark aerosol are encountered may have played a role. This effect is illustrated in a scatterplot of PSAP and photoacoustic light absorption measurements as shown in Figure 11, based on the data shown in Figure 10. PSAP values are lower than photoacoustic values, even with no scattering correction as also observed during the Reno Aerosol Optics Study when aerosol with low single scatter albedos were studied [Sheridan et al., 2005].

[40] Nine days later conditions had dramatically changed. The oil tank fire was extinguished, though a new fire at Fort Ord near Marina, California, had broken out. By contrast, this fire looked very white to observers. The fuel source was local vegetation and possibly abandoned structures. Figures 12a and 12b show a two-part time series of photoacoustic and PSAP measurements of aerosol light absorption at $676 \mathrm{~nm}$ and $660 \mathrm{~nm}$, respectively. Notice that the PSAP values are generally in excess of photoacoustic values as a result of not subtracting the scattering offset caused by the "white" particles on the PSAP measurements. The scatterplot in Figure 13a quantifies the comparison of PSAP and photoacoustic measurements, and shows the PSAP values are larger by a factor of 1.33. A hypothetical constant aerosol single scattering albedo of 0.943 was first used to calculate the scattering coefficient from the photoacoustic values, and then $2 \%$ of 


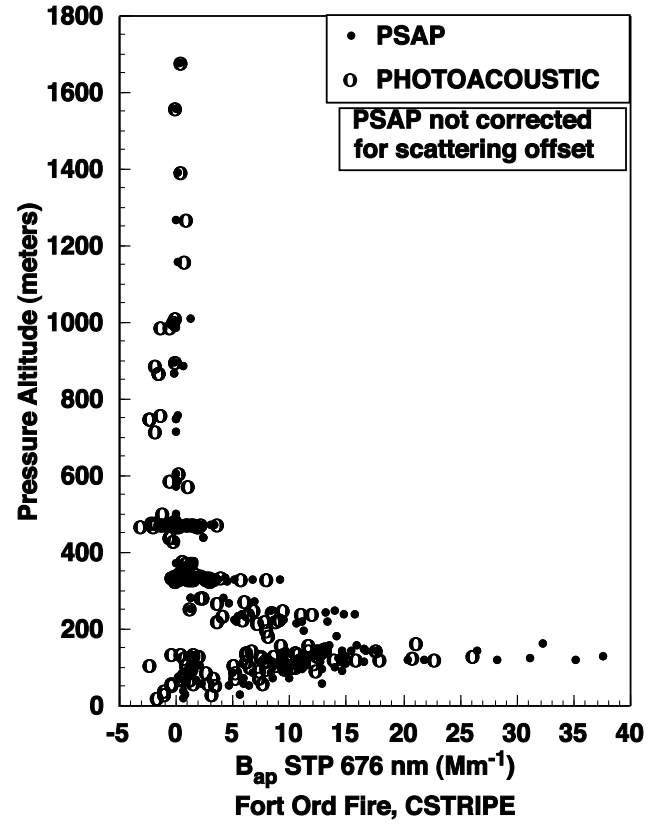

Figure 14. Vertical profile of aerosol light absorption from during the Fort Ord fire, CSTRIPE project, near Seaside, California, on 18 July 2003. Note that most of the smoke was below $400 \mathrm{~m}$ and levels aloft were much lower.

this hypothetical scattering amount was subtracted from the PSAP values as implied by the Bond correction [Bond et al., 1999; Virkkula et al., 2005]. This value of single scattering albedo was chosen to optimize agreement of data from these instruments, and was accomplished as a sensitivity study to give a feel for the magnitude of the PSAP scattering cross section for this aerosol composition. This single scattering albedo is consistent with the visual observations of the smoke. Finally, Figure 14 shows a vertical profile of light absorption from this flight for both PSAP and photoacoustic data. The fire plume was confined to levels below about $350 \mathrm{~m}$ and light absorption above $1 \mathrm{~km}$ was quite low.

[41] The choice of a single scattering albedo of 0.943 was evaluated by computing aerosol light scattering using Mie theory and particle size distributions from aircraft measurements. Light scattering was approximated using three aerosol sizing instruments deployed on the Twin Otter: The Dual Autostatic Classifier Aerosol Detector System (DACADS), which measured mobility diameter from $0.012 \mathrm{~mm}$ to $0.7 \mathrm{~mm}$; the Passive Cavity Aerosol Spectrometer (PCASP), which estimates the diameter of individual particles in the $0.1 \mathrm{~mm}$ to $3 \mathrm{~mm}$ range on the basis of the intensity of light scattered by angles ranging from $35^{\circ}$ to $155^{\circ}$; and the Cloud and Aerosol Spectrometer (CAS), which estimates the size of individual particles in the $0.7 \mathrm{~mm}$ to $100 \mathrm{~mm}$ size range on the basis of the intensity of light scattered by $4^{\circ}-13^{\circ}$. Particle refractive indices were chosen to be $(1.5,0.01)$ and $(1.5$, 0.02 ) for this sensitivity study, where the first and second numbers are the real and imaginary parts of the refractive index. Time series of light absorption were computed from these scattering calculations by assuming single scattering albedos in the range of 0.92 to 0.96 . While the single scattering albedo (and hence particle refractive index) appeared to vary during the Fort Ord fire, the value of 0.943 was a reasonable midrange value to use for the semiquantitative subtraction of the scattering amount from the PSAP data. This sensitivity study indicates that the PSAP scattering correction given in Figure 13b is reasonable.

\section{Conclusions}

[42] Long-range transport of aerosol from intense fires [Bodhaine et al., 1992; Damoah et al., 2004] is likely a common feature of the climate system. In situ characterization of such smoke adds much insight and complements remote sensing methods. This paper shows the feasibility of using resonant photoacoustic instrumentation for aircraft sampling of aerosol light absorption. Purely acoustical issues associated with use of a microphone on an aircraft were discussed first, and it was shown that it is reasonable to expect the microphone transducer to maintain its calibration aloft. Then an example of aerosol light absorption from very long range transport was presented as well as examples from flights close to the source of both very dark fires where aerosol light absorption dominates extinction, and very "white" fires where aerosol scattering dominates extinction. A metric was described to use when assessing the photoacoustic data quality aloft. The photoacoustic instrument has its very unique advantage in its large dynamic range that makes it suitable to measure aerosol light absorption both very near fire sources as well as far downwind. The photoacoustic instrument provides a nonfilter based measurement method, and it further constrains the uncertainties in our understanding of aerosol light absorption.

[43] Acknowledgments. Photoacoustic instrument development was supported by the National Science Foundation, grant ATM-0216572, and the Desert Research Institute. The IOP in Oklahoma was supported by the Department of Energy Atmospheric Radiation Measurement program. CSTRIPE was supported by the Office of Naval Research, and photoacoustic instrument participation was supported by the National Science Foundation, grant ATM-0340423. We are especially grateful to the Twin Otter pilots for their enthusiastic and competent work and to all participants of both projects for their enthusiastic support and assistance. Patrick J. Sheridan of NOAA's Climate Monitoring and Diagnostic Laboratory provided essential guidance and assistance with evaluation of particle loss issues associated with the aircraft inlet system. We acknowledge the insights provided by David S. Covert of the University of Washington.

\section{References}

Adams, K. M., L. I. Davis Jr., S. M. Japar, and D. R. Finley (1990a), Realtime, in situ measurement of atmospheric optical absorption in the visible via photoacoustic spectroscopy-IV. Visibility degradation and aerosol optical properties in Los Angeles, Atmos. Environ., Part A, 24, 605-610. Adams, K. M., L. I. Davis Jr., S. M. Japar, D. R. Finley, and R. A. Cary (1990b), Measurement of atmospheric elemental carbon: Real-time data for Los Angeles during summer 1987, Atmos. Environ., Part A, 24, $597-$ 604

Anderson, T. L., S. J. Masonis, D. S. Covert, N. C. Ahlquist, S. G. Howell, A. D. Clarke, and C. S. McNaughton (2003), Variability of aerosol optical properties derived from in situ aircraft measurements during ACEAsia, J. Geophys. Res., 108(D23), 8647, doi:10.1029/2002JD003247.

Andreae, M. O. (2001), The dark side of aerosols, Nature, 409, 671-672. Arnott, W. P., H. Moosmüller, R. E. Abbott, and M. D. Ossofsky (1995), Thermoacoustic enhancement of photoacoustic spectroscopy: Theory and measurements of the signal to noise ratio, Rev. Sci. Instrum., 66(10), $4827-4833$.

Arnott, W. P., J. A. Lightfoot, R. Raspet, and H. Moosmüller (1996), Radial wave thermoacoustic engines: Theory and examples for refrigerators and high-gain narrow-bandwidth photoacoustic spectrometers, J. Acoust. Soc. Am., 99(2), 734-745.

Arnott, W. P., H. Moosmüller, C. F. Rogers, T. Jin, and R. Bruch (1999), Photoacoustic spectrometer for measuring light absorption by aerosols: Instrument description, Atmos. Environ., 33, 2845-2852. 
Arnott, W. P., H. Moosmüller, and J. W. Walker (2000), Nitrogen dioxide and kerosene-flame soot calibration of photoacoustic instruments for measurement of light absorption by aerosols, Rev. Sci. Instrum., 71(7), $4545-4552$.

Arnott, W. P., H. Moosmueller, and J. W. Walker (2003a), Photoacoustic instrument for measuring particles in a gas, USA Patent 6,662,627, Desert Res. Inst., Reno, Nev.

Arnott, W. P., H. Moosmüller, P. J. Sheridan, J. A. Ogren, R. Raspet, W. V. Slaton, J. L. Hand, S. M. Kreidenweis, and J. L. Collett (2003b), Photoacoustic and filter-based ambient aerosol light absorption measurements: Instrument comparisons and the role of relative humidity, J. Geophys. Res., 108(D1), 4034, doi:10.1029/2002JD002165.

Arnott, W. P., et al. (2005a), Evaluation of $1047 \mathrm{~nm}$ photoacoustic instruments and photoelectric aerosol sensors in source-sampling of black carbon aerosol and particle bound PAH's from gasoline and diesel powered vehicles, Environ. Sci. Technol., 39(14), 5398-5406.

Arnott, W. P., K. Hamasha, H. Moosmueller, P. J. Sheridan, and J. A. Ogren (2005b), Towards aerosol light absorption measurements with a 7-wavelength aethalometer: Evaluation with a photoacoustic instrument and a 3 wavelength nephelometer, Aerosol Sci. Technol., 39, 17-29.

Bodhaine, B. A., J. M. Harris, J. A. Ogren, and D. J. Hofmann (1992), Aerosol optical properties at Mauna Loa Observatory: Long-range transport from Kuwait?, Geophys. Res. Lett., 19(6), 581-584.

Bohn, D. A. (1988), Environmental effects on the speed of sound, J. Audio Eng. Soc., 36(4), 223-231.

Bond, T. C., T. L. Anderson, and D. Campbell (1999), Calibration and intercomparison of filter-based measurements of visible light absorption by aerosols, Aerosol Sci. Technol., 30(6), 582-600.

Bruce, C. W., and R. G. Pinnick (1977), In situ measurements of light absorption with a resonant cw laser spectrophone, Appl. Opt., 16, $1762-1765$.

Damoah, R., N. Spichtinger, C. Forster, P. James, I. Mattis, U. Wandinger, S. Beirle, T. Wagner, and A. Stohl (2004), Around the world in 17 daysHemispheric-scale transport of forest fire smoke from Russia in May 2003, Atmos. Chem. Phys. Disc., 4, 1449-1471.

Ferrare, R. A., B. Schmid, and S. E. Schwartz (2006), The Atmospheric Radiation Measurement Program May 2003 Intensive Operations Period examining aerosol properties and radiative influences: Preface to special section, J. Geophys. Res., doi:10.1029/2005JD006908, in press.

Gorbunov, G., R. S. Hamilton, and R. Hitzenberger (2002), Modeling radiative transfer by aerosol particles on a filter, Aerosol Sci. Technol., $36(2), 123-135$.

Horvath, H. (1997), Systematic deviations of light absorption measurements by filter transmission methods, J. Aerosol Sci., 28, S55-S56.

Japar, S. M., and D. K. Killinger (1979), Photoacoustic and absorption spectrum of airborne carbon particulate using a tunable dye laser, Chem. Phys. Lett., 66, 207-209.

Japar, S. M., and A. C. Szkarlat (1981), Measurement of diesel vehicle exhaust particulate using photoacoustic spectroscopy, Combust. Sci. Technol., 24, 215-219.

Johnson, R. H., R. Gerlach, L. J. Thomas III, and N. M. Amer (1981), Loss mechanisms in resonant spectraphones, Appl. Opt., 21(1), 81-89.

Kamm, R. D. (1976), Detection of weakly absorbing gases using a resonant optoacoustic method, J. Appl. Phys., 47, 3550-3558.

Kirchstetter, T. W., T. Novakov, and P. V. Hobbs (2004), Evidence that the spectral dependence of light absorption by aerosols is affected by organic carbon, J. Geophys. Res., 109, D21208, doi:10.1029/2004JD004999.

Moosmüller, H., W. P. Arnott, C. F. Rogers, J. C. Chow, C. A. Frazier, L. E. Sherman, and D. L. Dietrich (1998), Photoacoustic and filter measurements related to aerosol light absorption during the Northern Front Range Air Quality Study (Colorado 1996/1997), J. Geophys. Res., 103(D21), 28,149-28,157.

Patel, C. K. N., E. G. Burkhardt, and C. A. Lambert (1974), Spectroscopic measurements of stratospheric nitric oxide and water vapor, Science, 184, $1173-1176$

Petzold, A., and R. Niessner (1992), In situ measurements on carbon aerosols with photoacoustic spectroscopy, Proc. SPIE Int. Soc. Opt. Eng., 1716, 510-516.
Petzold, A., and R. Niessner (1994), The photoacoustic soot sensor for black carbon monitoring, paper presented at Fifth International Conference on Carbonaceous Particles in the Atmosphere, Berkeley, Calif.

Petzold, A., and R. Niessner (1995), The photoacoustic soot sensor (pass)-validation for airborne particulate carbon, J. Aerosol Sci., 26, s759-s760.

Petzold, A., and M. Schönlinner (2004), Multi-angle absorption photometry-A new method for the measurement of aeorsol light absorption and atmospheric black carbon, J. Aerosol Sci., 35, 421-441.

Petzold, A., H. Schloesser, P. J. Sheridan, W. P. Arnott, J. A. Ogren, and A. Virkkula (2005), Evaluation of multi-angle absorption photometry for measuring aerosol light absorption, Aerosol Sci. Technol., 39, 4051.

Raspet, R., W. V. Slaton, W. P. Arnott, and H. Moosmüller (2003), Evaporation-condensation effects on resonant photoacoustics of volatile aerosols, J. Atmos. Oceanic Technol., 20(5), 685-695.

Reid, J. S., P. V. Hobbs, C. Liousse, and J. V. Martins (1998), Comparisons of techniques for measuring shortwave absorption and black carbon content of aerosols from biomass burning in Brazil, J. Geophys. Res., 103(D24), 32,031-32,040.

Roessler, D. M. (1984), Photoacoustic insight on diesel exhaust particles, Appl. Opt., 23, 1148-1155.

Roessler, D. M., and F. R. Faxvog (1980), Photoacoustic determination of optical absorption to extinction ratio on aerosols, Appl. Opt., 19, 578581

Rosengren, L.-G. (1975), Optimal optoacoustic detector design, Appl. Opt., 14, 1960-1976.

Sheridan, P. J., D. J. Delene, and J. A. Ogren (2001), Four years of continuous surface aerosol measurements from the Department of Energy's Atmospheric Radiation Program Southern Great Plains Cloud and Radiation Testbed site, J. Geophys. Res., 106, 20,735-20,748.

Sheridan, P. J., et al. (2005), The Reno aerosol optics study: An evaluation of aerosol absorption measurement methods, Aerosol Sci. Technol., 39, $1-16$.

Strawa, A. W., et al. (2006), In situ measurement of aerosol optical properties made during the DOE aerosol IOP: 1. Comparison of extinction and scattering coefficients, J. Geophys. Res., doi:10.1029/2005JD006056, in press.

Terhune, R. W., and J. E. Anderson (1977), Spectrophone measurements of the absorption of visible light by aerosols in the atmosphere, Opt. Lett., $1(2), 70-72$.

Virkkula, A., N. C. Ahlquist, D. S. Covert, W. P. Arnott, P. J. Sheridan, P. K. Quinn, and D. J. Coffman (2005), Modification, calibration and a field test of an instrument for measuring light absorption by particles, Aerosol Sci. Technol., 39, 68-83.

Wang, J., R. C. Flagan, J. H. Seinfeld, H. H. Jonsson, D. R. Collins, P. B. Russell, B. Schmid, J. Redemann, J. M. Livingston, and S. Gao (2002), Clear-column radiative closure during ACE-Asia: Comparison of multiwavelength extinction derived from particle size and composition with results from Sun photometry, J. Geophys. Res., 107(D23), 4688, doi:10.1029/2002JD002465

Weingartner, E., H. Saathoff, M. Schnaiter, N. Streit, B. Bitnar, and U. Baltensperger (2003), Absorption of light by soot particles: Determination of the absorption coefficient by means of aethalometers, J. Aerosol Sci., $34,1445-1463$

W. P. Arnott, H. Moosmüller, and J. W. Walker, Division of Atmospheric Sciences, Desert Research Institute, Reno, NV 89512, USA. (pat@dri.edu) G. Buzorius and H. H. Jonsson, Naval Postgraduate School, Monterey, CA 93943, USA.

W. C. Conant, R. C. Flagan, and J. H. Seinfeld, California Institute of Technology, Pasadena, CA 91125, USA.

R. A. Elleman, Department of Atmospheric Sciences, University of Washington, Seattle, WA 98195, USA. 